\title{
The Storm-Track Response to Idealized SST Perturbations in an Aquaplanet GCM
}

Article

Published Version

Brayshaw, D. J., Hoskins, B. J. and Blackburn, M. (2008) The Storm-Track Response to Idealized SST Perturbations in an Aquaplanet GCM. Journal of the Atmospheric Sciences, 65 (9). pp. 2842-2860. ISSN 1520-0469 doi: https://doi.org/10.1175/2008JAS2657.1 Available at https://centaur.reading.ac.uk/1303/

It is advisable to refer to the publisher's version if you intend to cite from the work. See Guidance on citing.

Published version at: http://dx.doi.org/10.1175/2008JAS2657.1

To link to this article DOI: http://dx.doi.org/10.1175/2008JAS2657.1

Publisher: American Meteorological Society

Publisher statement: () Copyright 2008 of the American Meteorological Society. The AMS Copyright Policy is available on the AMS web site at http://www.ametsoc.org

All outputs in CentAUR are protected by Intellectual Property Rights law, including copyright law. Copyright and IPR is retained by the creators or other copyright holders. Terms and conditions for use of this material are defined in the End User Agreement.

www.reading.ac.uk/centaur 
Central Archive at the University of Reading

Reading's research outputs online 


\title{
The Storm-Track Response to Idealized SST Perturbations in an Aquaplanet GCM
}

\author{
DAVID JAMES BRAYSHAW \\ Walker Institute, Department of Meteorology, University of Reading, Reading, United Kingdom \\ BRIAN HOSKINS \\ Department of Meteorology, University of Reading, Reading, United Kingdom \\ Michael BLACKBURN \\ Walker Institute, Department of Meteorology, University of Reading, Reading, United Kingdom
}

(Manuscript received 24 October 2007, in final form 24 January 2008)

\begin{abstract}
The tropospheric response to midlatitude SST anomalies has been investigated through a series of aquaplanet simulations using a high-resolution version of the Hadley Centre atmosphere model (HadAM3) under perpetual equinox conditions.

Model integrations show that increases in the midlatitude SST gradient generally lead to stronger storm tracks that are shifted slightly poleward, consistent with changes in the lower-tropospheric baroclinicity. The large-scale atmospheric response is, however, highly sensitive to the position of the SST gradient anomaly relative to that of the subtropical jet in the unperturbed atmosphere. In particular, when SST gradients are increased very close to the subtropical jet, then the Hadley cell and subtropical jet is strengthened while the storm track and eddy-driven jet are shifted equatorward. Conversely, if the subtropical SST gradients are reduced and the midlatitude gradients increased, then the storm track shows a strong poleward shift and a well-separated eddy-driven jet is produced. The sign of the SST anomaly is shown to play a secondary role in determining the overall tropospheric response.

These findings are used to provide a new and consistent interpretation of some previous GCM studies concerning the atmospheric response to midlatitude SST anomalies.
\end{abstract}

\section{Introduction}

The growth of transient eddies (storms) in the midlatitude regions is primarily driven by baroclinic processes. Consistent with this, storms tend to form most frequently and strongly in regions of high baroclinicity. Following Hoskins and Valdes (1990), a commonly used measure of this baroclinicity is the maximum Eady growth rate:

$$
\sigma=-\frac{0.31 g}{N \Theta_{0}} \frac{\partial \bar{\theta}}{\partial y}=\frac{0.31 f}{N} \frac{\partial \bar{u}}{\partial z}
$$

Observational evidence clearly shows that baroclinicity and the midlatitude storm tracks are far from being

Corresponding author address: D. J. Brayshaw, The Walker Institute for Climate Research, Department of Meteorology, Earley Gate, University of Reading, P.O. Box 243, Reading, Berkshire RG6 6BB, United Kingdom.

E-mail: d.j.brayshaw@rdg.ac.uk zonally uniform. Surface features such as orography, land-sea contrast, and asymmetric SST distributions exert a profound effect on the distribution and characteristics of the midlatitude storm tracks, particularly in the Northern Hemisphere. However, such features can be considered to be modifiers of an otherwise statistically axisymmetric storm track (e.g., Cash et al. 2005 and Inatsu et al. 2002), which is, at the most fundamental level, driven by the differences in the absorption of solar radiation between the equator and the poles.

A traditional route to investigate the role of the storm tracks has therefore been to examine the relationship between the characteristics of the zonal-mean "background" state and the midlatitude storm tracks that form upon it (Simmons and Hoskins 1978, 1980; Edmon et al. 1980; James 1987; Thorncroft et al. 1993). Such studies have shown that the storm-track eddies tend to form in the strongly baroclinic region on the poleward side of the subtropical jet and modify the mean flow to create a deeper, barotropic "eddy-driven" jet at higher latitudes. The barotropic shear that this 
process adds to the zonal mean flow modifies (or even inhibits) the growth of further eddies.

The zonal-mean characteristics of the midlatitude flow are therefore a product of the processes that enhance baroclinicity and the storm track that reduces the baroclinicity creating a more barotropic flow. Considering now the baroclinicity-forming processes in the midlatitudes, there are two key sources: first, the Hadley circulation that is driven by tropical heating gradients and enhances the subtropical temperature gradient and the jet [as described by authors such as Held and Hou (1980) and Kim and Lee (2001)] and, second, surface temperature gradients in the midlatitudes (such as SST fronts).

Lee and Kim (2003) used a series of idealized experiments to investigate the relationship of the storm tracks and the eddy-driven jets to the strength of the subtropical jet. In particular, a strong subtropical jet led to the preferred region for eddy activity being immediately on the northern flank of the subtropical jet and a single jet structure was seen in the troposphere. Conversely, a weaker subtropical jet led to the eddy activity being displaced $20^{\circ}-30^{\circ}$ poleward of the subtropical jet and a split jet structure was produced (i.e., the eddy-driven jet was well separated from the subtropical jet).

This provides a basis from which an understanding of climatological features such as the North Pacific storm track's "midwinter minimum" can begin to be built. The midwinter minimum is a period where storm activity is suppressed despite the presence of a strong, highly baroclinic, subtropical jet. Nakamura and Sampe (2002) used reanalysis data to show that in such periods the intense subtropical jet can trap eddy activity within its core, away from the strong surface temperature gradients of the Kuroshio in the Pacific Ocean, consistent with the behavior seen in Lee and Kim (2003). However, in the idealized experiments of Lee and Kim (2003), the thermal structure of the midlatitude regions is constantly relaxed back to a specified profile and it is therefore unclear what effect local surface-driven changes in the midlatitude baroclinicity (e.g., forced by a SST front) would have in this context.

Strong meridional gradients in surface temperatures are a common feature of many midlatitude regions. Storm tracks in general have long been associated with the strong surface temperature gradients produced by ocean currents, in particular the Gulf Stream and the Kuroshio in the Atlantic and Pacific but also the Antarctic Circumpolar Current in the Southern Hemisphere. Hoskins and Valdes (1990) discuss the role that the surface westerlies generated by the storm track play in driving the ocean currents responsible for the SST fronts that feedback and support the storm track. Na- kamura et al. (2004) emphasize this role and further propose that there are two characteristic relationships: First, given a relatively "weak" background subtropical jet, the storm track and SST front form somewhat poleward of the subtropical jet and create a separate eddydriven jet. The second situation occurs when the subtropical jet is "strong," trapping eddy activity within the jet core, weakening the surface westerlies, and the SST front occurs in a region much farther poleward than in the weak case.

The validity of these characteristic relationships cannot be assessed purely through reanalysis data. In particular, the strength of the Hadley cell (and therefore the subtropical jet) is closely linked to the tropospheric temperature profile (and therefore the SST profiles) in the tropics and subtropics (Held and Hou 1980). Trenberth and Stepaniak (2003) and Kim and Lee (2001), among others, also emphasize the role of the midlatitude eddies in driving the Hadley cell as part of a "seamless" transport of energy poleward from the equator.

This present study separates these mechanisms to provide the basis for a better understanding of the overall response. To achieve this, aquaplanet GCM integrations featuring zonally symmetric boundary conditions are performed and analyzed. The SSTs are prescribed (removing the feedback of the atmosphere upon the ocean) and a series of SST perturbations affecting both the subtropical jet and the midlatitude SST fronts are considered.

Further experiments are performed with zonally asymmetric SST patterns. These experiments resemble those performed by Inatsu et al. (2003) who added zonal wavenumber-1 SST anomalies to a zonally uniform background SST field. They argued that the condensational heating produced by the storm track was highly important in driving the upper-tropospheric stationary wave response, consistent with the earlier stationary wave studies by Hoskins and Valdes (1990). This present study further illuminates this response by examining the zonally asymmetric response as a progression from one quasi-zonal equilibrium structure to another. This therefore provides insight into the challenging problem of determining the time-mean response to a midlatitude SST anomaly (Kushnir et al. 2002) and its relationship to the background jet position (Peng et al. 1997; Ting and Peng 1995), thereby linking the storm-track (and stationary wave) response to a SST front with the response to a SST anomaly.

The structure of the present study is as follows: Section 2 outlines the model and the experimental configuration. Section 3 contains a description of the control 

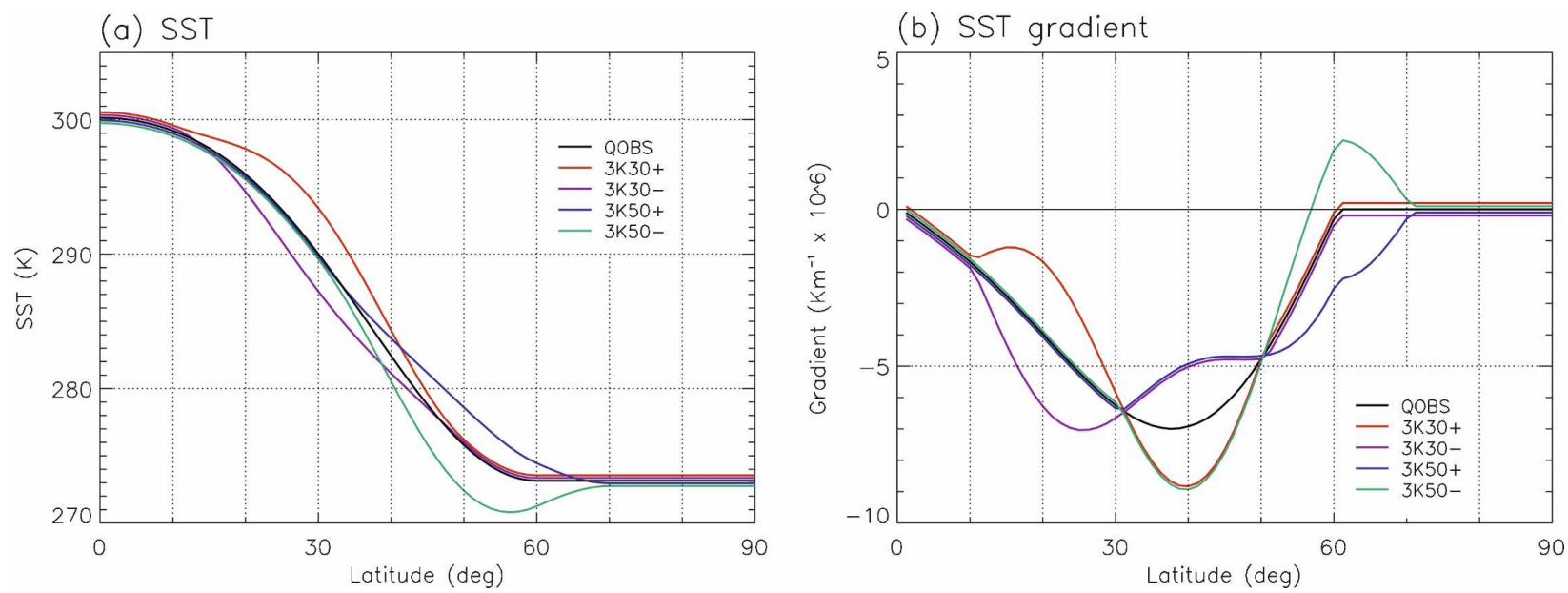

FIG. 1. The zonally symmetric aquaplanet experiments: (a) SST profile (K) and (b) SST gradient $\left(\mathrm{K} \mathrm{m}^{-1}\right)$. The SST profiles and gradients for QOBS and $3 \mathrm{~K} 50+/-$ are identical in the region $0^{\circ}$ to $30^{\circ}$ latitude as are those of QOBS and $3 \mathrm{~K} 30+/-$ in the region $50^{\circ}$ to $70^{\circ}$ latitude. In (b) the SST gradients for $3 \mathrm{~K} 30+/ 3 \mathrm{~K} 50-$ and also for $3 \mathrm{~K} 30-/ 3 \mathrm{~K} 50+$ are identical from $30^{\circ}$ to $50^{\circ}$ latitude. In the regions $0^{\circ}-10^{\circ}$ and $70^{\circ}-90^{\circ}$ latitude the SST profiles and gradients are identical in all the experiments. Small constants have been added to the lines in these plots to aid visibility.

run state. Sections 4 and 5 present results from the zonally symmetric and zonally asymmetric experiments, respectively. Finally, sections 6 and 7 provide a discussion and summary of the conclusions. The estimation of eddy-driven surface westerly winds associated with transient fluxes is discussed in the appendix.

\section{Experimental design}

The Hadley Centre atmosphere model (HadAM3) GCM used in this study is described in detail by Pope et al. (2000) and has been used extensively for climate projections and within climate research. It is a hydrostatic, gridpoint model with an Eulerian advection scheme and a full set of parameterizations. The standard model configuration has a resolution of $2.5^{\circ}$ latitude by $3.75^{\circ}$ longitude with 19 vertical levels (N48L19), but throughout this paper a resolution of $1.25^{\circ}$ latitude by $1.875^{\circ}$ longitude with 30 vertical levels (N96L30) is used. While the standard resolution has been found to reproduce the large-scale characteristics of the storm tracks quite well (Stratton 2004), the increased resolution further improves this representation. In particular, the change from N48 to N96 produces an increase in the strength of the storm tracks and their position is shifted poleward, leading to better agreement with observations (Stratton 2004; Greeves et al. 2007; Pope and Stratton 2002).

Each integration contains $3 \mathrm{yr}$ of data $(6 \mathrm{yr}$ for the control integration) following an initial spinup period and is performed under perpetual equinox conditions. Using perpetual equinox conditions leads to the following two key benefits:
- shorter integrations are required to detect statistically significant differences between them;

- the midlatitudes of the Northern and Southern Hemispheres should be symmetric in their statistics and the data can be averaged over both, doubling the effective length of the output time series.

However, it should be noted that the storm tracks are generally at their strongest in midwinter (particularly in the Atlantic) and therefore the perpetual equinox storm tracks may be somewhat weaker than those that would be observed under perpetual winter solstice conditions (as used by, e.g., Inatsu et al. 2003 and Kushnir and Held 1996).

\section{a. The experimental configuration}

The integrations are based upon a zonally symmetric aquaplanet configuration using the "QOBS" SST profile (Neale and Hoskins 2000), hereafter referred to as experiment QOBS or the control run. The SST profile is shown by the black lines in Fig. 1 and is given (in ${ }^{\circ} \mathrm{C}$ ) by

$$
\mathrm{SST}=\frac{T_{\max }}{2}\left[2-\sin ^{4}\left(\frac{3 \phi}{2}\right)-\sin ^{2}\left(\frac{3 \phi}{2}\right)\right],
$$

where $T_{\max }=27.0^{\circ} \mathrm{C}$ and $\phi$ denotes the latitude. At latitudes above $60^{\circ}$, the SST is set to $0^{\circ} \mathrm{C}$.

Two sets of perturbation experiments are then performed. One set features a zonal wavenumber-1 SST anomaly with amplitude $3^{\circ} \mathrm{C}$, latitudinally centered at either $30^{\circ}$ latitude (experiment $3 \mathrm{~K} 30 \mathrm{WAVE}$ ) or $50^{\circ}$ 
(a) 3K3OWAVE

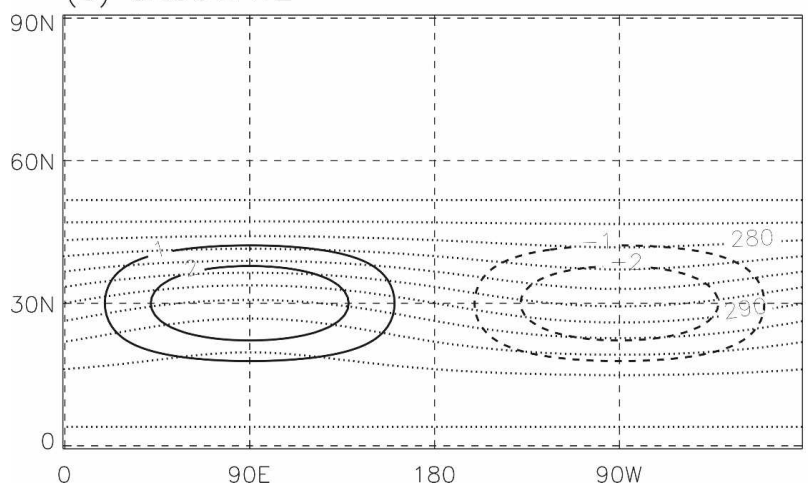

(b) 3K5OWAVE

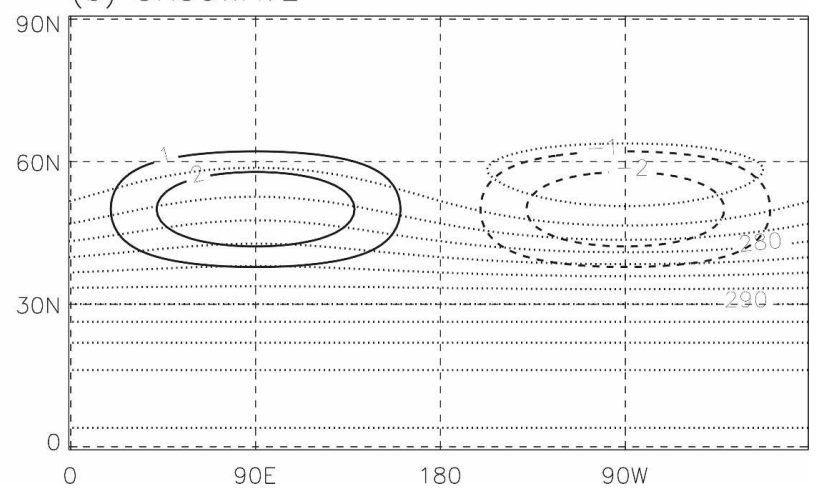

FIG. 2. The SST profiles of the zonally asymmetric aquaplanet experiments: (a) 3K30WAVE and (b) 3K50WAVE. Dotted lines show absolute SSTs (K) and solid and dashed contours show SST anomalies (dashed for negative).

latitude (experiment 3K50WAVE). The form of the anomalies, shown in Fig. 2, is similar to those used in Inatsu et al. (2003) and is given by

$$
\Delta \mathrm{SST}=T_{0}\left[\sin (\lambda) \cos ^{2}\left(\frac{\pi}{2} \frac{\phi-\phi_{0}}{\phi w}\right)\right],
$$

where $\lambda$ denotes the longitude, $\phi_{0}$ is the latitudinal center of the wave, $\phi_{w}=20^{\circ}$ is the latitudinal width, and $T_{0}=3^{\circ} \mathrm{C}$ is the maximum amplitude.

The other set of SST anomaly experiments $(3 \mathrm{~K} 30+$, $3 \mathrm{~K} 30-, 3 \mathrm{~K} 50+$, and $3 \mathrm{~K} 50-$ ) are zonally symmetric and correspond to meridional cross sections through the warmest and coldest parts of the WAVE experiments. The latitudinal profiles of SST and its gradient generated by these experiments are shown by the colored lines in Fig. 1. A summary of all the experiments is provided in Table 1.

The formation of sea ice is in general prevented as the SST profiles are designed such that the minimum temperature is $0^{\circ} \mathrm{C}$. However, in the $3 \mathrm{~K} 50-$ and 3K50WAVE experiments, the SSTs are slightly below $0^{\circ} \mathrm{C}$ in a small region at around $50^{\circ}-60^{\circ}$ latitude and sea ice formation may be possible in this region. However, the fact that surface temperatures significantly below zero are not found in these experiments suggests that the existence of possible small regions of sea ice is not of importance to the results of these experiments and the conclusions drawn from them.

\section{b. Data analysis}

The storm tracks are analyzed using standard single level Eulerian (variance and covariance map) techniques (e.g., the heat flux by transient eddies, $\overline{v^{\prime} T^{\prime}}$, on the 850 -hPa surface). Such diagnostics can provide an insight into the interactions between the large-scale flow and the storm track, particularly when characteristic "active" measures, such as $\overline{v^{\prime} T^{\prime}}$ and $\overline{u^{\prime} v^{\prime}}$, are considered together in the context of the $\mathbf{E}$ vector and its divergence (Hoskins et al. 1983, hereafter HJW). Here the divergence of the horizontal component of the $\mathbf{E}$ vector at $250 \mathrm{hPa}$ and the vertical component of $\mathbf{E}$ at $850 \mathrm{hPa}$ will be normalized in such a way as to provide an estimate of the surface westerly wind that could be in equilibrium with them in the presence of simple surface drag. The details are given in the appendix. These estimates allow comparison of the horizontal and vertical components of the $\mathbf{E}$ vector with the actual surface wind and comparison between experiments. However, the vertical component estimate is probably an upper bound on the surface wind associated with it and this should be borne in mind in the discussion below. A "passive" storm-track measure, geopotential height

TABLE 1. The idealized aquaplanet experiments. The column ZS denotes whether or not the experiments are zonally symmetric. The column Years refers to the number of years of data following an initial spinup period. All experiments are symmetric about the equator.

\begin{tabular}{lccl}
\hline \hline Experiment & ZS & Years & \multicolumn{1}{c}{ Description } \\
\hline QOBS & Y & 6 & Control run using the QOBS profile [Eq. (2)] \\
3K30WAVE & N & 3 & QOBS + 3K zonal wavenumber-1 anomaly at 30 latitude [Eq. (3)] \\
3K50WAVE & N & 3 & As for 3K30WAVE but with anomaly at 50 latitude \\
$3 \mathrm{~K} 30+$ & $\mathrm{Y}$ & 3 & Meridional cross section through the warmest part of 3K30WAVE \\
$3 \mathrm{~K} 30-$ & $\mathrm{Y}$ & 3 & Meridional cross section through the coldest part of 3K30WAVE \\
$3 \mathrm{~K} 50+$ & $\mathrm{Y}$ & 3 & Meridional cross section through the warmest part of 3K50WAVE \\
$3 \mathrm{~K} 50+$ & $\mathrm{Y}$ & 3 & Meridional cross section through the coldest part of 3K50WAVE \\
\hline
\end{tabular}


variance at $850 \mathrm{hPa}$, is also used to describe the storm track.

The (co)variance maps are calculated after a 2-6-day bandpass filter is applied to the raw data components (which are recorded at 6-h intervals). The filter used is a Lanczos filter (Duchon 1979) with a total width of 30 days, which isolates the 2-6-day window well. The results are not sensitive to moderate variations in filter width.

The significance of the differences between the storm tracks diagnosed in the various experiments are tested using the Wilcoxon-Mann-Whitney (WMW) method (see, e.g., Wilks 1995) as the Gaussian assumption implicit in the standard $t$ test was found to be inappropriate. The WMW method is nonparametric and makes no such assumption. To ensure that the data used for significance testing is serially uncorrelated the 6-hourly storm-track data has been resampled at 5-day intervals (the autocorrelation of the storm-track variables was found to be close to zero beyond this time scale). The dominant signals discussed in this paper are all significant at the $90 \%$ level.

\section{The control integration}

The control integration (driven by the QOBS SST profile) produces a storm track and jet that are statistically axisymmetric when time averaged over the length of the run. The zonal-mean characteristics of this structure are shown in Fig. 3. As in Neale and Hoskins (2000), the troposphere has a split intertropical convergence zone (not shown) and a single, broad jet structure in each hemisphere located on the poleward edge of the Hadley cell (Fig. 3a).

The baroclinicity measured over the depth of the troposphere (Fig. 3b) is greatest at the jet axis, dropping off on the poleward side where the jet becomes more barotropic (Figs. 3a,b). This is consistent with the eddy activity acting through its heat flux to accelerate the westerly flow in the lower troposphere while decelerating it in the upper troposphere so as to maintain thermal wind balance. Using the scaling given in the appendix, the thermal transient fluxes may be capable of maintaining surface westerlies of order $7 \mathrm{~m} \mathrm{~s}^{-1}$. The momentum fluxes maximize their impact in the upper troposphere but drive a surface westerly that is estimated to be of order $3 \mathrm{~m} \mathrm{~s}^{-1}$ (Fig. 3c). These estimates enable the consistency between the storm-track fluxes and the strength of the surface westerlies to be seen, and comparison to be made to between experiments. The values, particularly that from the momentum flux,
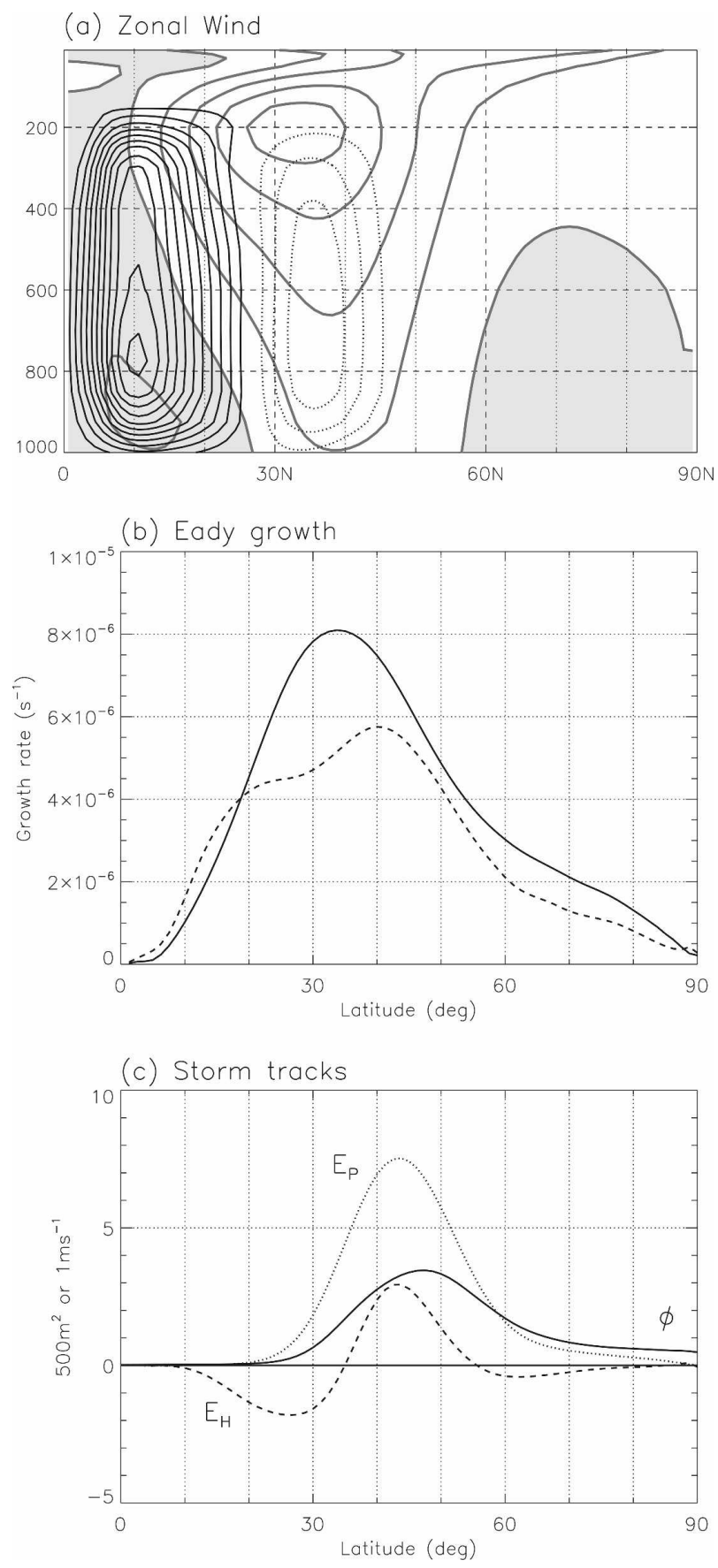

FIG. 3. The zonally symmetric control run (QOBS): (a) Zonal wind (thick gray contours, contour interval $=10 \mathrm{~m} \mathrm{~s}^{-1}$, negative values shaded), and zonal-mean meridional circulation (contour interval $=2 \times 10^{10} \mathrm{~kg} \mathrm{~s}^{-1}$, dashed for negative). (b) Eady growth rates measured between $925-250 \mathrm{hPa}$ (solid line) and 925-775 hPa (dashed line). (c) Storm-track diagnostics: bandpass-filtered geopotential height variance at $850 \mathrm{hPa}$ (solid); normalized $\mathbf{E}$ vector (vertical component $850 \mathrm{hPa}$ shown by the dotted line and horizontal divergence at $250 \mathrm{hPa}$ is shown by the dashed line). See the appendix for a discussion of $\mathbf{E}$ vector normalization. 
are underestimates because of the use of time-filtered data and the normalization factors chosen. ${ }^{1}$

The peaks in the westerly forcing as given by the $\mathbf{E}$ vector lie slightly to the poleward side of the peak in the whole troposphere baroclinicity. Indeed, they are more closely collocated with the peaks in the lower-tropospheric baroclinicity as measured by the Eady growth rate between 925 and $775 \mathrm{hPa}$ (Figs. 3b,c). This lowlevel measure of baroclinicity also contains suggestions of a double peak: a small peak at approximately $25^{\circ}$ and a larger peak at approximately $40^{\circ}$ latitude. The larger of the two peaks is in the region of peak SST gradients (cf. Figs. 1b and 3b). The smaller peak, however, has no such local boundary forcing mechanism and is, instead, associated with the poleward side of the tropically driven Hadley circulation and with the subtropical jet (Fig. 3a).

The single jet structure shown in Fig. 3a may therefore be considered to be a composite of two distinct jets: the baroclinic subtropical jet near $25^{\circ}$ latitude (driven by the Hadley circulation and tropical heating) and the more barotropic eddy-driven jet near $40^{\circ}$ latitude (associated with the eddy heat and momentum transports).

It is difficult to compare the atmospheric state produced in the control run to that in reanalysis data owing to the lack of zonal asymmetries in the model. The gradients associated with the QOBs SST profile perhaps most clearly resemble those of the North Pacific, with the peak SST gradient near $40^{\circ}$, though the overall temperature of the profile is typically $2^{\circ}-5^{\circ} \mathrm{C}$ cooler in QOBS than in the western North Pacific. The resulting upper-tropospheric jet strength (around $45 \mathrm{~m} \mathrm{~s}^{-1}$ ) and position (between $25^{\circ}$ and $40^{\circ}$ latitude) is comparable to that seen in the boreal autumn (September-November) season according to the 40-yr European Centre for Medium-Range Weather Forecasts (ECMWF) ReAnalysis (ERA-40) (Uppala et al. 2005). Other features of the simulation (e.g., precipitation, Hadley cell width, storm-track strength) are similarly comparable.

The QOBS control run can also be related to the situation in the North Atlantic sector. Caution must be exercised, however, as not only is the tropical North Atlantic warmer than the QOBS profile, but also the

\footnotetext{
${ }^{1} \mathbf{E}$ vectors derived from the bandpass-filtered data have a similar structure but typically half the magnitude of those derived from unfiltered data. Also, the factor scaling the eddy momentum flux to estimate the surface wind could reasonably be increased by a factor of two to give optimum results. However, tuning the parameters in this way would be inappropriate for these calculations, which are intended to produce approximate values that are nonetheless consistent across experiments. These underestimates should be noted throughout this paper.
}

North Atlantic Ocean has a more distinct SST gradient between the subtropical and subpolar gyres, particularly in the western half of the basin near the Gulf Stream where the storm-track core tends to form. Furthermore, in this region of the North Atlantic, the peak SST gradients lie farther poleward than those in QOBS, closer to $45^{\circ}-50^{\circ}$. Such changes are perhaps consistent with a stronger subtropical component of the jet and weaker storm activity in QOBS (Nakamura et al. 2004; Nakamura and Shimpo 2004). Given these caveats, the principal mechanisms controlling the jet structure and storm-track strength that are the subject of this paper are considered to be relevant to both the Atlantic and the Pacific.

\section{The effect of variations in axisymmetric SST profiles}

\section{a. Changes in the SST gradients of the midlatitudes}

Consider first the experiments $3 \mathrm{~K} 50+$ and $3 \mathrm{~K} 50-$. In these experiments, the tropical SST profile (equatorward of $\sim 30^{\circ}$ latitude) is identical to that of the control run and therefore the tropically driven part of the subtropical jet (i.e., that driven by the tropical SST distribution) is largely unchanged.

In the extratropics, however, the SST gradient is substantially modified (Fig. 1b). For experiment 3K50+, the gradient is weakened relative to the control run at $40^{\circ}$ latitude and increased near $60^{\circ}$ latitude. The changes in the lower-tropospheric Eady growth rate (Fig. 4b) are consistent with this, with a reduction of baroclinicity near $40^{\circ}$ and an increase around $60^{\circ}$ latitude, yielding a broad low-level baroclinic zone across the midlatitudes.

The storm track in experiment $3 \mathrm{~K} 50+$ shows little change in the region close to $60^{\circ}$ latitude (Fig. 5a), implying that the change in the SST gradient here has little impact. This is perhaps unsurprising given that the main storm-track region is concentrated closer toward the equator near $40^{\circ}-45^{\circ}$ latitude. In that region, the decreased strength of the SST gradient does have a profound effect, weakening the storm track in each of the measures shown in Fig. 5a, consistent with a weakening of the estimated driving of the surface winds of order $2 \mathrm{~m} \mathrm{~s}^{-1}$ relative to the control run. The weakened storm track is also shifted slightly equatorward as shown most clearly in the changes in the geopotential height variance and momentum flux diagnostics.

Despite these large changes in the storm track, the changes in the jet structure of experiment $3 \mathrm{~K} 50+$ are modest (Fig. 6a). The eddy-driven jet component is weaker, shifting the overall jet pattern slightly equatorward and weakening the surface winds. The intensity of 

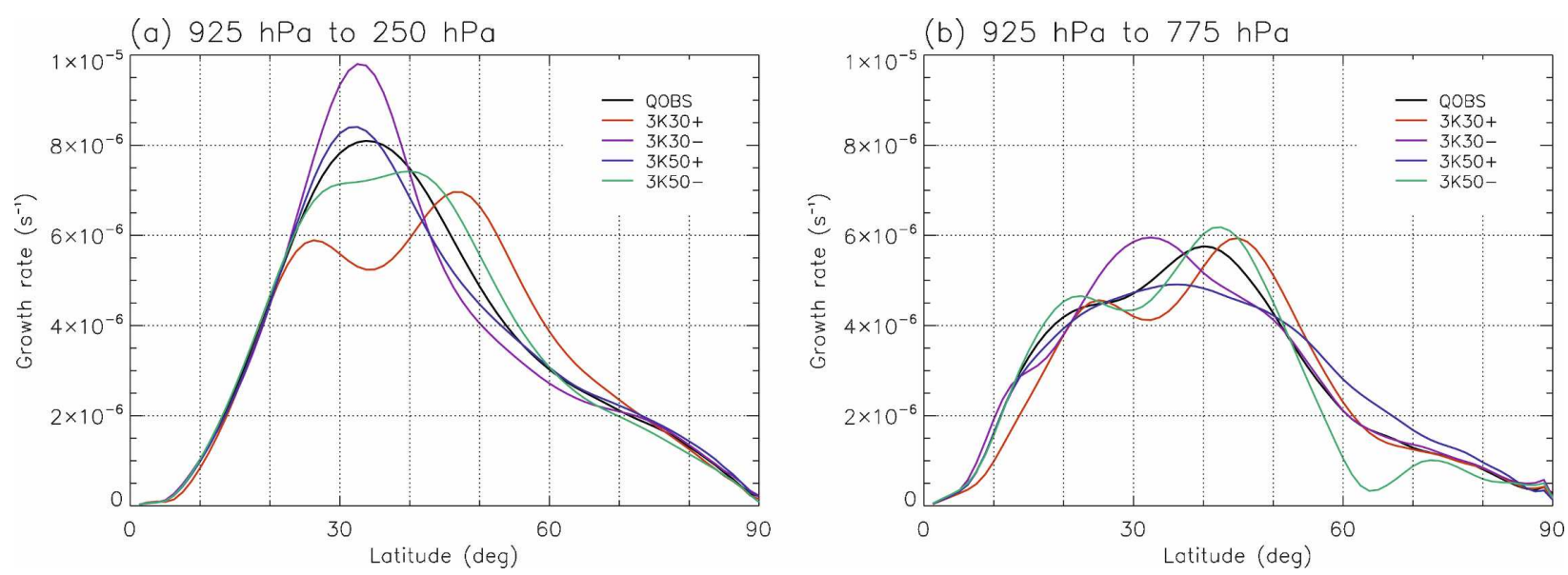

FIG. 4. The Eady growth rate for the zonally symmetric aquaplanet experiments measured (a) between 925 and 250 hPa and (b) between 925 and $775 \mathrm{hPa}$.
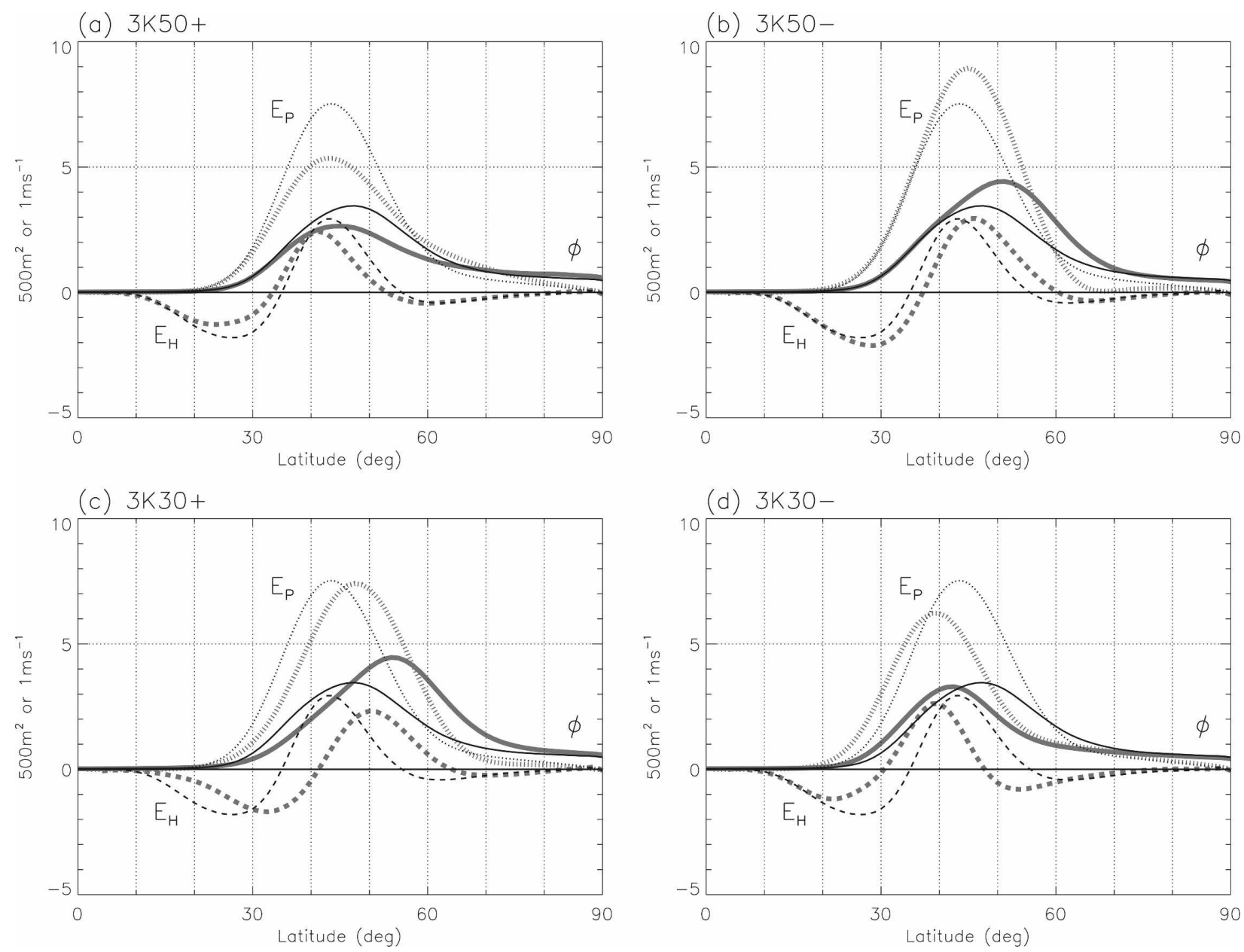

FIG. 5. The zonally averaged storm tracks in each of the zonally symmetric aquaplanet experiments: bandpass-filtered geopotential height variance at $850 \mathrm{hPa}$ (solid) and normalized $\mathbf{E}$ vector (vertical component at $850 \mathrm{hPa}$ shown by the dotted line and horizontal divergence at $250 \mathrm{hPa}$ is shown by the dashed line). In each case, thick gray lines show the experiment and thin black lines the control QOBS integration. (a) Expt 3K50+, (b) expt 3K50-, (c) expt 3K30+, and (d) expt 3K30-. See the appendix for a discussion of $\mathbf{E}$ vector normalization. 
(a) $3 K 50+$

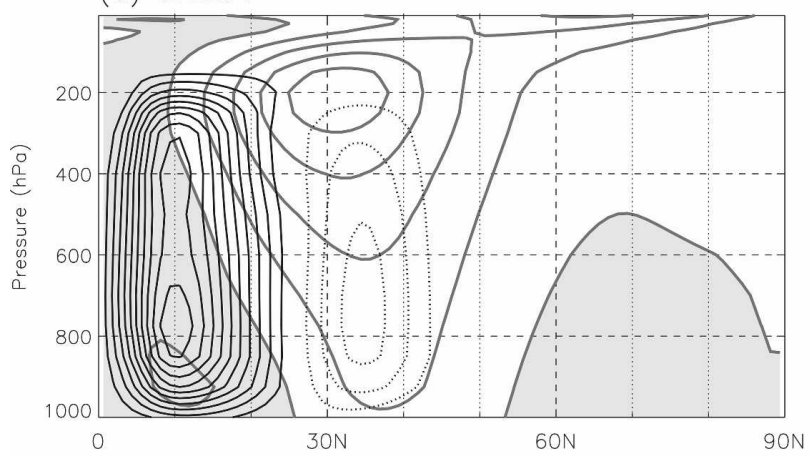

(c) $3 K 30+$

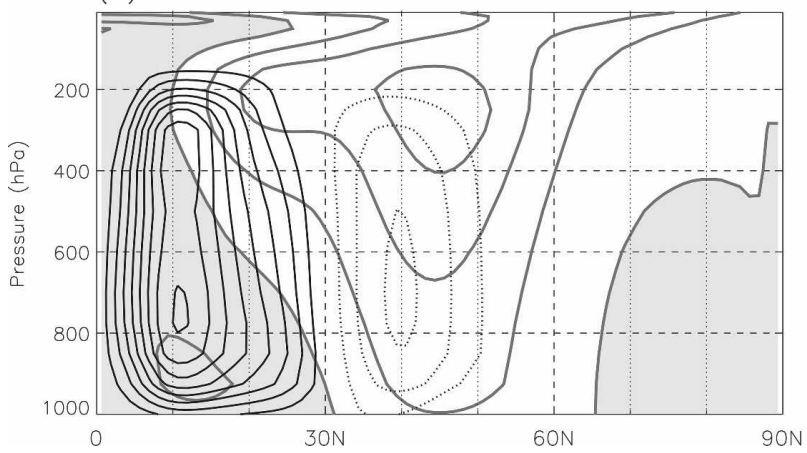

(b) $3 K 50-$

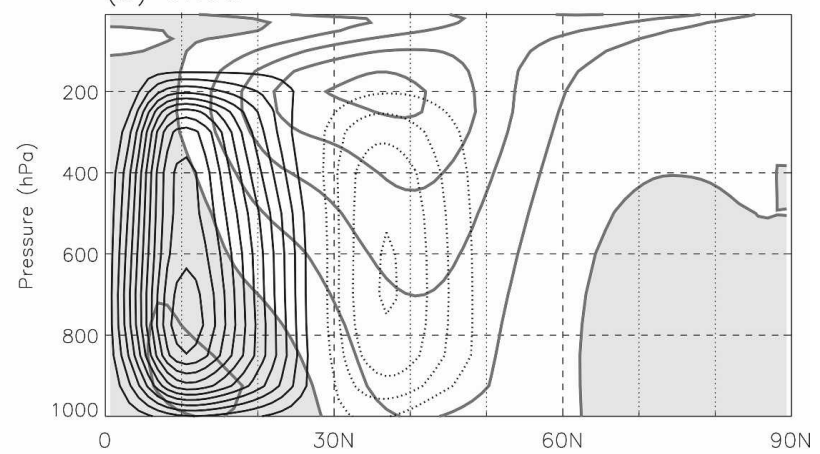

(d) $3 \times 30-$

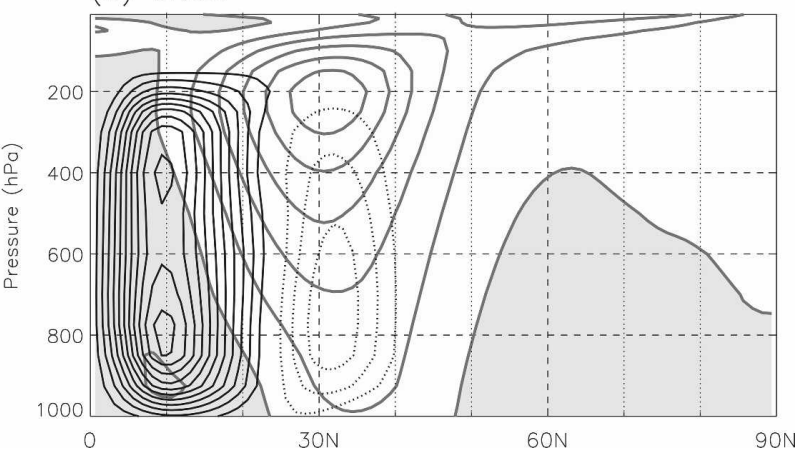

FIG. 6. The zonal-averaged jet structures in the zonally symmetric aquaplanet experiments: Zonal wind (thick gray contours, contour interval $=10 \mathrm{~m} \mathrm{~s}^{-1}$, negative values shaded) and zonal-mean meridional circulation (contour interval $=2 \times 10^{10} \mathrm{~kg} \mathrm{~s}{ }^{-1}$, dashed for negative) for (a) expt 3K50+, (b) expt 3K50-, (c) expt 3K30+, and (d) expt 3K30-.

the eddy-driven part of the Hadley cell is also slightly weaker, as seen most clearly in the lower troposphere, consistent with the reduction in the strength of the midlatitude storm track (Kim and Lee 2001).

For experiment $3 \mathrm{~K} 50-$, the inverse situation applies. The SST gradient (and consequently the lower-tropospheric baroclinicity) is increased relative to the control run at $40^{\circ}$ latitude and decreased at $60^{\circ}$ (Figs. $1 \mathrm{~b}$ and $4 \mathrm{~b})$. As in experiment $3 \mathrm{~K} 50+$, there is little response by the storm track to the change in baroclinicity at $60^{\circ}$ latitude (although there is a slight decrease in the normalized vertical component of the $\mathbf{E}$ vector here, shown in Fig. 5b). The increase in the SST gradient near $40^{\circ}$ latitude, however, produces an increase in the stormtrack strength along with a poleward shift of around $2^{\circ}-3^{\circ}$ latitude, which is consistent with an enhancement of the estimated surface winds on the order of 1-2 $\mathrm{m} \mathrm{s}^{-1}$ relative to the control run (Fig. 5b).

In experiment $3 \mathrm{~K} 50-$, the jet is shifted slightly poleward and is more closely coincident with the region of peak midlatitude SST gradient than that in the control run (Fig. 6b). The surface winds in the midlatitudes are stronger (consistent with the increased strength of the eddy-driven jet) and the Hadley cell in the lower tro- posphere is slightly enhanced, consistent with the stronger midlatitude transient fluxes (Kim and Lee 2001).

\section{b. Changes in subtropical SST gradients}

The interpretation of experiments $3 \mathrm{~K} 30+$ and $3 \mathrm{~K} 30-$ is more complex, as the SST anomalies influence the SST gradients both in the tropics and in the extratropics (Fig. 1b). However, in the midlatitudes (between $30^{\circ}$ and $50^{\circ}$ latitude), the SST gradients in experiment $3 \mathrm{~K} 30+$ are identical to those in experiment $3 \mathrm{~K} 50-$, and therefore the differences in the responses between these two experiments can be linked to the reduced tropical SST gradients in experiment $3 \mathrm{~K} 30+$ (recall that the differences in the SST profile poleward of $50^{\circ}$ latitude were found to have little impact on the storm tracks, as described in section 4a). Experiment $3 \mathrm{~K} 30$ - may be similarly compared with experiment $3 \mathrm{~K} 50+$ but with increased tropical SST gradients.

Consider first experiment $3 \mathrm{~K} 30+$. In this experiment, the weakening of the SST gradient in the subtropics (near $20^{\circ}$ latitude, Fig. 1b) is consistent with a weakening of the Hadley cell relative to either the control run or experiment $3 \mathrm{~K} 50-$ (Fig. 6c). This weakening leads 
to a weaker subtropical jet and weaker baroclinicity for midlatitude storm growth close to $25^{\circ}$ latitude (Fig. 4a).

In the extratropics, the SST gradient near $40^{\circ}$ latitude is increased (Fig. 1b) and the peak in the SST gradient is shifted poleward relative to the control run. From the discussion presented in section $4 \mathrm{a}$, this can be expected to increase storm-track activity and shift the track poleward, bringing it into a closer relationship with the strengthened SST gradients in the midlatitudes.

The storm-track diagnostics for experiment $3 \mathrm{~K} 30+$ (Fig. 5c) show a strong poleward shift relative to the control run. Indeed, this shift (approximately $5^{\circ}-6^{\circ}$ in each of the storm-track measures) is slightly stronger than that in experiment $3 \mathrm{~K} 50-\left(\right.$ typically nearer $2^{\circ}-3^{\circ}$ ). This difference is consistent with the weakening of the tropically driven component of the subtropical jet in experiment $3 \mathrm{~K} 30+$, which provides a less fertile region for storm growth immediately on the poleward side of the subtropical jet (Lee and Kim 2003).

Figure $5 \mathrm{c}$ clearly shows that the peak storm activity (measured by the variance of geopotential height at 850 $\mathrm{hPa}$ ) is increased in experiment $3 \mathrm{~K} 30+$ relative to the control run, consistent with experiment $3 \mathrm{~K} 50-$. However, the intensity of the normalized thermal transient fluxes shows little change in experiment $3 \mathrm{~K} 30+$ relative to the control and are significantly weaker than those in experiment $3 \mathrm{~K} 50-$. This is again consistent with the weakening of the subtropical baroclinicity (Fig. 4a) associated with the weakening of the tropically driven component of the subtropical jet in experiment $3 \mathrm{~K} 30+$ (i.e., there is less baroclinicity available to fuel storm growth). Similarly, the peak normalized divergence of the momentum transients is weakened compared to that in experiment 3K50- (cf. Fig. 5b with Fig. 5c). This is consistent with the weakening of the meridional gradients of zonal wind associated with the subtropical jet, shown in Fig. 6c.

Compared with the control run, in experiment $3 \mathrm{~K} 30+$ the combination of the weakened subtropical jet, the poleward shift in the normalized thermal transients, and the smearing out of the normalized divergence of the momentum transients over a wider range of latitudes leads to a much broader jet structure, as shown in Fig. 6c. At $50^{\circ}$ latitude, the enhanced thermal transient fluxes are consistent with driving stronger surface westerlies on the order of $1-2 \mathrm{~m} \mathrm{~s}^{-1}$ and the momentum fluxes suggest a similar result (Fig. 5c). Given the underestimate of the driving of the surface flow by the transients, particularly that associated with the momentum flux, these estimates are consistent with the actual change in the surface winds at this location (approximately $4 \mathrm{~m} \mathrm{~s}^{-1}$, cf Fig. 3a with Fig. 6c). The resulting jet therefore features a much more prominent barotropic eddy-driven component near $45^{\circ}$ than that in either the control run (Fig. 3a) or experiment 3K50(Fig. 6b).

For experiment $3 \mathrm{~K} 30-$, the situation is reversed. In the subtropics, the SST gradients are enhanced (Fig. 1b), leading to a stronger Hadley circulation and subtropical jet (Fig. 6d) than in either the control run or experiment 3K50+ (Figs. 3a and 6a). Consistent with this, the baroclinicity in the subtropics is strongly enhanced (Fig. 4a).

In the extratropics in experiment $3 \mathrm{~K} 30-$ the SST gradients are reduced (Fig. 1b). As in experiment $3 \mathrm{~K} 50+$, this leads to a weakening of the midlatitude baroclinicity in the lower troposphere (Fig. 4b) and a weakened and equatorward shifted storm track (Fig. $5 \mathrm{~d})$. However, the storm-track intensity in experiment $3 \mathrm{~K} 30-$ is stronger and shifted farther equatorward than that in experiment 3K50+ (cf. Fig. 5a and Fig. 5d) despite the two experiments having identical extratropical SST gradients. This is consistent with the storm track in experiment $3 \mathrm{~K} 30$ - being intensified (relative to experiment $3 \mathrm{~K} 50+$ ) by the enhanced subtropical baroclinicity associated with the stronger subtropical jet (approximately $58 \mathrm{~m} \mathrm{~s}^{-1}$ in the jet core). A subtropical jet of this strength might also tend to trap the storm-track eddies into the jet region, consistent with the storm track shifting equatorward relative to experiment $3 \mathrm{~K} 50+$ (Nakamura and Sampe 2002). The enhancement of the storm track by the intensified subtropical jet therefore occurs despite mechanisms such as the barotropic governor (James 1987), which might tend to weaken the storm track in the presence of a strong subtropical jet.

The equatorward shift and the weakening of the storm tracks in experiment $3 \mathrm{~K} 30$ - leads to an equatorward shift and weakening of the eddy-driven jet compared with the control. Indeed, at $45^{\circ}$ latitude the weakening of the thermal transient fluxes is consistent with a weakening of the estimated surface winds by the order of $2-3 \mathrm{~m} \mathrm{~s}^{-1}$, with the weakened momentum transient flux divergence suggesting a similar reduction. Given the expected underestimation, this is consistent with the actual changes in the surface winds (approximately $3 \mathrm{~m} \mathrm{~s}^{-1}$, cf Fig. 3a with Fig. 6d). As a consequence, the overall zonal flow structure displays a single, highly baroclinic jet (Fig. 6d).

\section{c. The sign of the SST anomalies}

In addition to consideration of SST gradients, it is important to consider the sign of the SST anomaly as warm anomalies can be expected to increase the availability of latent heat for the atmosphere while cold anomalies would decrease it, consistent with the Clausius-Clapeyron relationship. Enhanced latent heat re- 


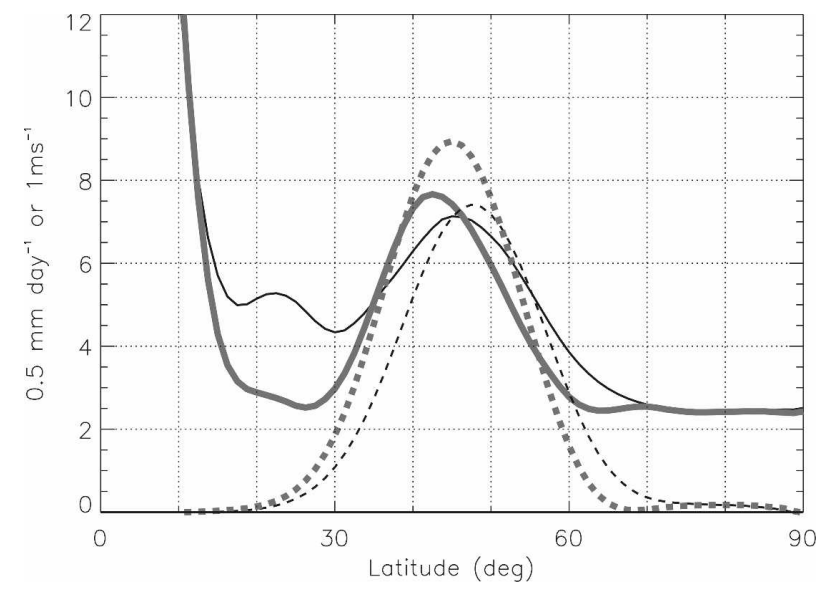

FIG. 7. Zonal-mean precipitation (solid lines) and the normalized vertical component of the $\mathbf{E}$ vector at $850 \mathrm{hPa}$ (dotted lines) in the zonally symmetric aquaplanet experiments $3 \mathrm{~K} 30+$ (thin black lines) and 3K50- (thick gray lines).

lease might then be expected to invigorate individual eddies and, perhaps, therefore the storm track leading to a stronger eddy-driven jet. The opposite conclusion is often drawn from energy balance arguments where it is noted that the same storm will transport more energy poleward in a warmer climate so that fewer or weaker storms are required to transport a given quantity of energy, thereby suggesting a weaker storm track. Such energy balance arguments are, however, not directly applicable in the experimental setup used here with prescribed SSTs.

Figure 7 shows that the midlatitude peak in precipitation (which is representative of the latent heat release in the middle troposphere) is actually stronger in the cold SST anomaly experiment 3K50 - than in the warm SST anomaly experiment $3 \mathrm{~K} 30+$, although it is more tightly confined between $30^{\circ}$ and $50^{\circ}$ latitude (consistent with the colder SSTs to the north in 3K50- and the warmer SSTs to the south in $3 \mathrm{~K} 30+$ ). Consistent with this the eddy heat flux (shown by the dotted lines in Fig. 7 ) is stronger in experiment $3 \mathrm{~K} 50-$ than $3 \mathrm{~K} 30+$. However, despite this increase, the jet structure produced by experiment $3 \mathrm{~K} 50$ - remains much more single in structure and subtropically dominated than that in $3 \mathrm{~K} 30+$ (cf. Fig. 6b with Fig. 6c, where the eddy-driven jet is almost completely separated from the subtropical jet).

This discussion suggests that the changes in the SST gradient in the neighborhood of the tropically driven component of the subtropical jet are more important in determining the upper-tropospheric response than the sense of the midlatitude SST anomaly. Indeed, the reduced subtropical SST gradients in experiment $3 \mathrm{~K} 30+$ (and the consequent weakening of the Hadley cell and the subtropical jet associated with it) lead to a much stronger splitting of the overall jet structure, even though the midlatitude eddy heat fluxes are weaker than those in experiment 3K50-. However, midlatitude latent heat release (typically an order of magnitude greater than sensible heat release in these aquaplanet integrations) cannot be completely discarded as a feedback mechanism. Indeed, the equatorward shift in the midlatitude precipitation in experiment $3 \mathrm{~K} 50-$ (relative to experiment $3 \mathrm{~K} 30+$, Fig. 7) is consistent with the equatorward shift in the peak of the eddy heat flux region and the production of a less dramatic split between the eddy-driven and subtropical jets.

\section{d. Summary: Axisymmetric experiments}

In summary, these zonally symmetric aquaplanet experiments show that the storm track and jet responses to an SST anomaly are better understood by considering the changes in SST gradient patterns rather than the SST anomaly itself. In particular, the storm-track response is highly sensitive to the latitudinal location of the SST gradient anomaly as described in Table 2. An SST anomaly, latitudinally situated such that it modifies both subtropical and midlatitude SST gradients (as in

TABLE 2. A summary of the impacts of the changes in SST gradients from the zonally symmetric SST profile integrations. Upward and downward arrows indicate increases and decreases, whereas EQ and PW indicate equatorward and poleward shifts, respectively. STJ $=$ subtropical jet, SSTF $=$ SST front (the region of peak SST gradients), TDHC = tropically driven component of the Hadley cell, and LTBC = lower-tropospheric baroclinicity. An asterisk denotes that limiting mechanisms could occur (e.g., the barotropic governor) whereby further increases in baroclinicity lead to only small increases in storm-track strength.

\begin{tabular}{|c|c|c|c|c|c|}
\hline \multirow[b]{2}{*}{ SST gradient anomaly } & \multirow[b]{2}{*}{ Example expt } & \multicolumn{2}{|c|}{ Storm track } & \multirow[b]{2}{*}{ Jet splitting } & \multirow[b]{2}{*}{ Mechanism } \\
\hline & & Shift & Strength & & \\
\hline$\uparrow$ (subtropics) & $3 \mathrm{~K} 30-$ & EQ (toward STJ) & $\uparrow *$ & $\downarrow$ & TDHC $\uparrow$ \\
\hline$\downarrow$ (subtropics) & $3 \mathrm{~K} 30+$ & PW & $\downarrow$ & $\uparrow$ & $\mathrm{TDHC} \downarrow$ \\
\hline$\uparrow$ (midlat) & $3 \mathrm{~K} 30+/ 3 \mathrm{~K} 50-$ & PW (toward SSTF) & $\uparrow$ & $\uparrow$ & LTBC $\uparrow$ \\
\hline$\downarrow$ (midlat) & $3 \mathrm{~K} 30-/ 3 \mathrm{~K} 50+$ & EQ & $\downarrow$ & $\downarrow$ & LTBC $\downarrow$ \\
\hline$\uparrow$ (high lat) & $3 \mathrm{~K} 50+$ & No change & No change & No change & \\
\hline$\downarrow$ (high lat) & $3 \mathrm{~K} 50-$ & No change & No change & No change & \\
\hline
\end{tabular}


(a) Geopotential height variance $850 \mathrm{hPa}$

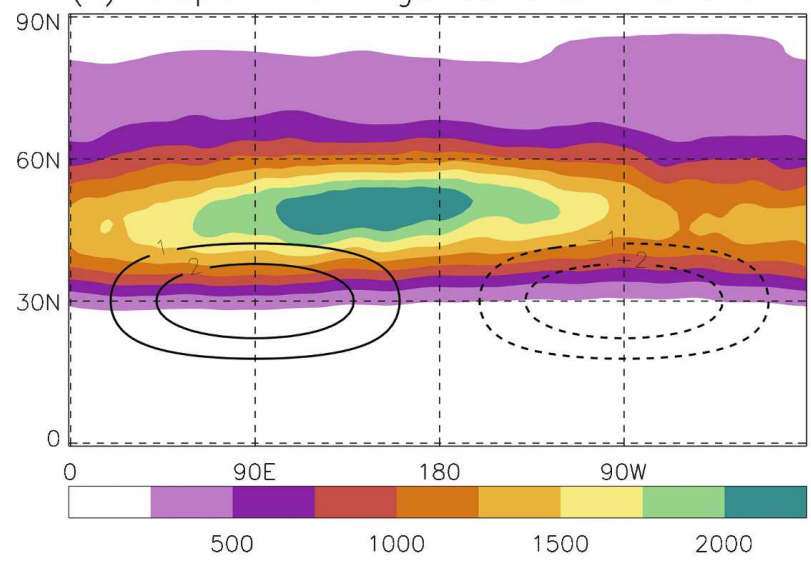

(c) Zonal wind $250 \mathrm{hPa}$

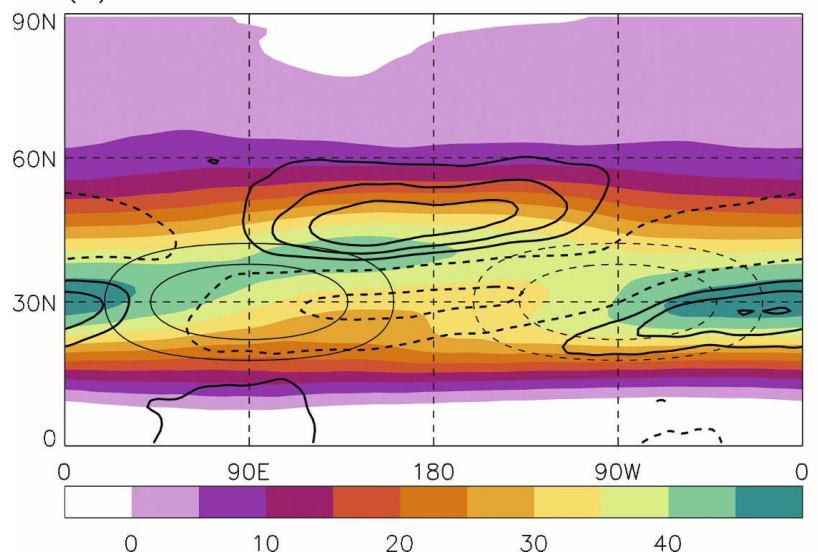

(b) Precipitation

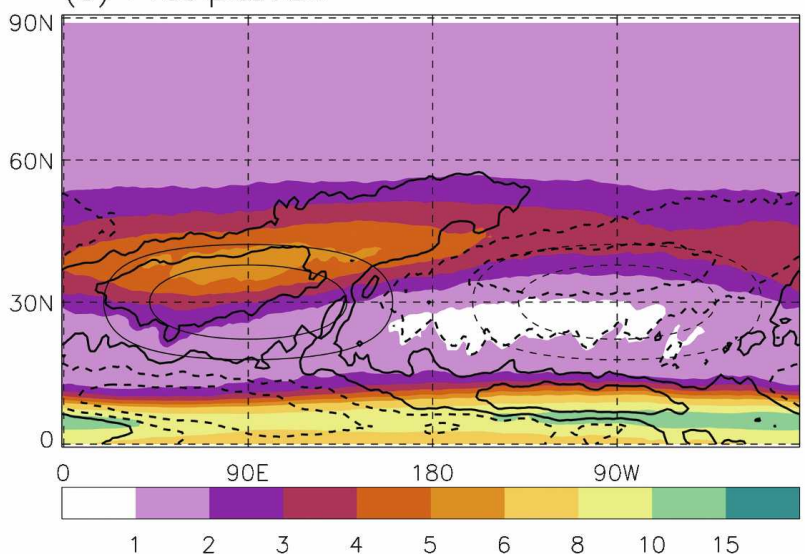

(d) Eady $850 \mathrm{hPa}$

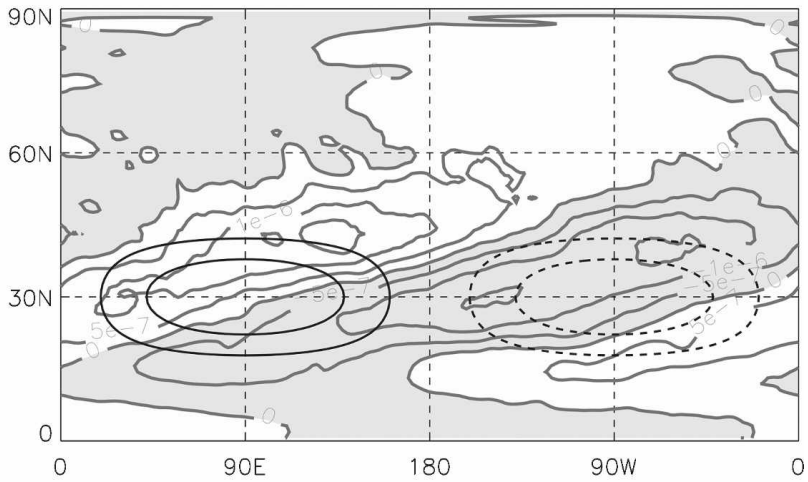

FIG. 8. Experiment 3K30WAVE: (a) Bandpass-filtered geopotential height variance at $850 \mathrm{hPa}\left(\mathrm{m}^{2}\right)$. (b) Precipitation: absolute in $\mathrm{mm}$ day $^{-1}$ (shading) and anomaly relative to control run shown by contours at \pm 0.25 and $1 \mathrm{~mm} \mathrm{day}^{-1}$. (c) Zonal wind at $250 \mathrm{hPa}$ : absolute in $\mathrm{m} \mathrm{s}^{-1}$ (shading) and anomaly relative to control run shown by thick contours at $\pm 2,4$, and $6 \mathrm{~m} \mathrm{~s}^{-1}$. (d) Eady growth rate anomaly (between 925 and $775 \mathrm{hPa}, \mathrm{s}^{-1}$ ) relative to control run, shaded for negative. In each panel, thin contours mark the SST anomalies.

experiments $3 \mathrm{~K} 30+/-)$, can therefore have a profound effect both on the storm track and the jet structure through changes in both the tropically driven component of the subtropical jet and the lower-tropospheric baroclinicity of the midlatitude storm-track region.

Table 2 further suggests that the tropospheric response to an SST gradient anomaly will change depending on its latitudinal position relative to the tropically driven subtropical jet component. The seasonal march of the Hadley cell and the subtropical jet can therefore lead to the same SST gradient anomaly having very different effects as it effectively moves between the high latitude, midlatitude, and subtropical regimes. This issue is discussed further in section 6 .

\section{Asymmetric SST distributions}

The response to the zonally asymmetric SST distribution of experiment 3K30WAVE is shown in Fig. 8 (the SST distribution itself can be seen in Fig. 2a). The strength of the storm track varies dramatically around the $40^{\circ}-50^{\circ}$ latitude band with the maximum intensity at different longitudes varying by almost a factor of 2 (Fig. 8a). This asymmetry will be diagnosed in terms of zonal variations in both the tropically driven subtropical jet structure and the locally driven near-surface baroclinicity.

Consider first the anomalies in the near-surface baroclinicity of the midlatitudes (Fig. 8d). The baroclinicity is reduced over (and downstream of) the weak SST gradients on the poleward side of the cold anomaly and enhanced over the strong SST gradients on the poleward side of the warm anomaly. This is consistent with stronger storm growth on the poleward and downstream side of the warm anomaly and weaker storm growth poleward and downstream of the cold anomaly. The eastward offset of the baroclinicity and storm-track 

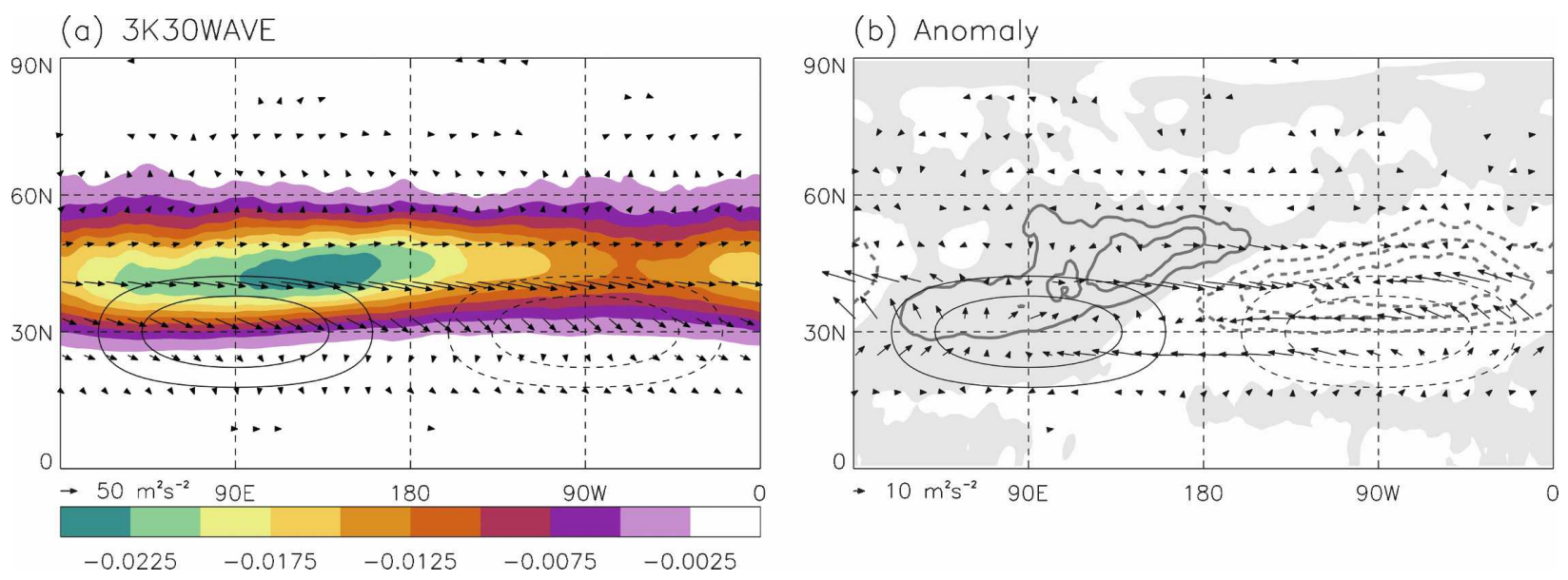

FIG. 9. Unnormalized E-vector diagrams for experiment 3K30WAVE: (a) Total bandpass-filtered $\mathbf{E}$ vector: vertical component at 850 $\mathrm{hPa}$ (shaded) and horizontal component at $250 \mathrm{hPa}$ (arrows). (b) E vector anomaly relative to the control run: vertical component at $850 \mathrm{hPa}$ (contours with negative values indicating stronger activity shown by the solid contours/shaded area), and horizontal component at $250 \mathrm{hPa}$ (arrows). The scale for the arrows is shown at the lower left of each panel.

anomalies relative to the strongest SST gradient anomalies is consistent with advection by the background westerly winds in the midlatitudes.

Consider now the changes in the subtropical jet structure. Near the cold SST anomaly, the tropical SST gradient is increased (similar to experiment $3 \mathrm{~K} 30-$ ), leading to intensified precipitation (Fig. 8b) and ascent (not shown) in the deep tropics (Fig. 8b). This ascent leads to stronger vortex shrinking in the upper troposphere, enhancing the subtropical jet to the east of the cold SST anomaly and shifting it slightly equatorward (Fig. 8c). This could be considered as a zonally localized enhancement of the Hadley circulation. Close to the warm SST anomaly, however, the situation is reversed (similar to experiment $3 \mathrm{~K} 30+$ ) with reduced precipitation and ascent in the deep tropics, leading to weaker vortex shrinking in the upper troposphere and a weaker subtropical jet to the poleward and eastern side. This modulation of the subtropical jet is consistent with the changes in the meridional position of the storm track relative to the zonally symmetric control run (QOBS). In particular, the poleward shift of storm activity on the downstream and poleward side of the warm SST anomaly (where the subtropical jet is weak) and the weaker equatorward shift at the downstream and poleward side of the cold SST anomaly (where the subtropical jet is strong) are similar to that seen in the zonally symmetric experiments $3 \mathrm{~K} 30+/-$, respectively (as described in section $4 \mathrm{~b}$ ). The longitudinal changes in the storm-track intensity (Fig. 8a) are similarly localized by the subtropical jet structure with increasing storm-track activity downstream of the strong subtropical jet region and decreasing storm activity downstream of the weak subtropical jet region.
The changes in the tropical circulation and SST gradients are also consistent with the changes in the lowertropospheric Eady growth rate equatorward of $30^{\circ}$ latitude (Fig. 8d) in that the weaker SST gradients and Hadley circulation to the south of the warm anomaly lead to weaker low-level baroclinicity while the situation is reversed on the equatorward side of the cold anomaly. However, these changes in the near-surface baroclinicity of the tropics are not important for the midlatitude storm tracks.

The storm-track localization in the 3K30WAVE experiment can be clearly seen in the $\mathbf{E}$ vector diagrams. Figure 9a shows the expected eastward-pointing $\mathbf{E}$ vector throughout the storm-track region, corresponding to the meridional extension of eddies and also equatorward pointing arrows on the equatorial flank, particularly on the downstream end. Compared with the control run, however, this meridional component is generally weaker so that equatorward and eastward of the cold SST anomaly, the anomalous $\mathbf{E}$ vector has a strong poleward component (Fig. 9b), indicating reduced poleward transport of momentum from the subtropical jet in the region. This is consistent with further enhancing the strength of the subtropical jet on the equatorward side of this region.

The normalized divergence of the $\mathbf{E}$ vector (as discussed in the appendix) is shown in Fig. 10a. While the field is somewhat noisy, particularly in terms of the divergence of the horizontal component (each of the quantities in Fig. 10 have been smoothed), the eddies clearly maintain a westerly anomaly downstream and poleward of the warm SST anomaly and an easterly anomaly downstream and poleward of the cold SST anomaly. Given the underestimate, the transient eddy 

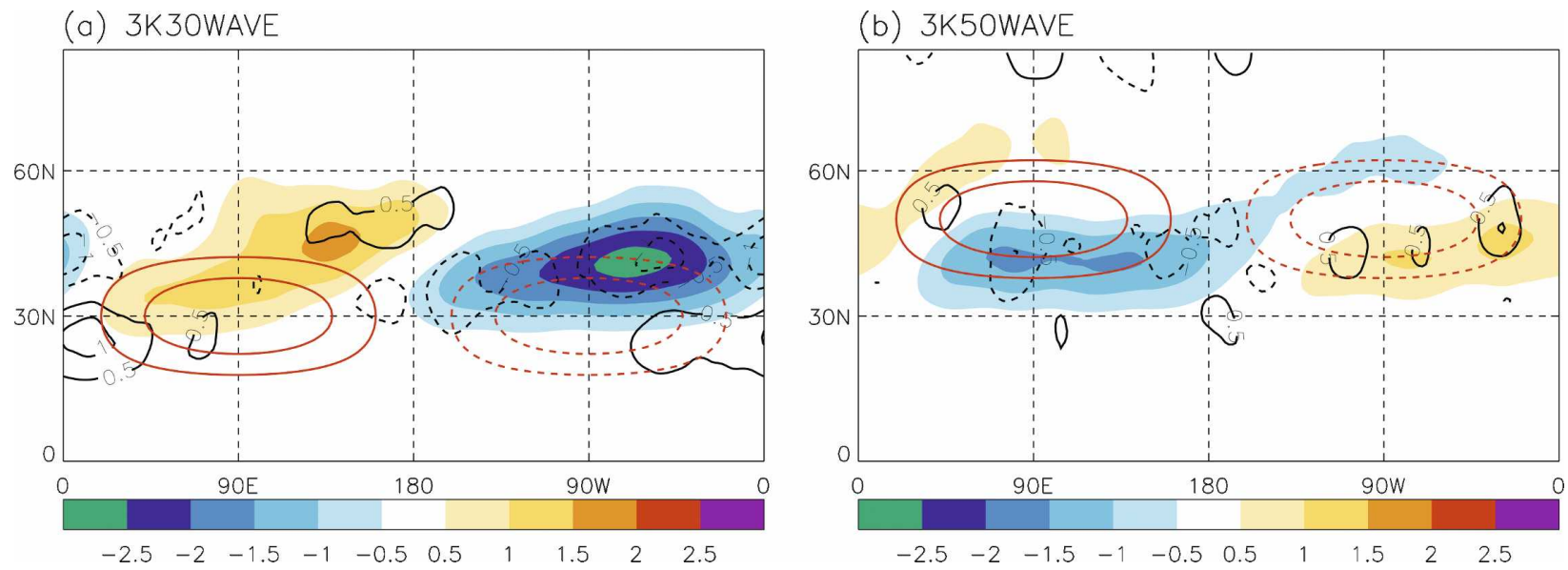

FIG. 10. Normalized E vector components (see the appendix for a discussion) anomalies relative to the control run: (a) Expt $3 \mathrm{~K} 30 \mathrm{WAVE}$ and (b) expt 3K50WAVE. Vertical component at $850 \mathrm{hPa}$ is shown by colors and horizontal divergence at $250 \mathrm{hPa}$ is shown by contours (the contour interval is identical to the color bar). The units in each case are $\mathrm{m} \mathrm{s}^{-1}$. Each field has been lightly smoothed prior to plotting to improve readability.

forcing is consistent with the actual longitudinal variation of the zonal wind at $1000 \mathrm{hPa}$ (approximately $4 \mathrm{~m} \mathrm{~s}^{-1}$ in Fig. 11a). The downstream offset of the extreme values in the zonal wind pattern relative to that of the forcing by the divergence of the $\mathbf{E}$ vector is consistent with the overall westerly background flow.

The surface pressure pattern produced by the SST anomalies in experiment 3K30WAVE is shown in Fig. 11a. A zonal wavenumber- 1 response, centered on $60^{\circ}$ latitude, is found with the low pressure center downstream and poleward of the enhanced SST gradient region (at $40^{\circ} \mathrm{N}, 90^{\circ} \mathrm{E}$ ). This pressure response has a broadly barotropic nature (despite a slight poleward tilt with height in the midlatitudes) throughout much of the extratropical troposphere (Fig. 11c), and is consistent with the barotropic nature of the enhancement of the jet around $45^{\circ}-50^{\circ}$ latitude (Figs. $8 \mathrm{c}$ and 11a). Figure $8 \mathrm{c}$ shows that there is a change with longitude from a subtropically dominated upper-tropospheric jet near $330^{\circ} \mathrm{E}$ (similar to that in experiment 3K30-, Fig. 6d) to an eddy-dominated jet near $150^{\circ} \mathrm{E}$ (similar to experiment $3 \mathrm{~K} 30+$, Fig. 6c). Near $180^{\circ}$ there is a double jet structure.

The storm track produced by experiment 3K50WAVE is, by contrast to experiment $3 \mathrm{~K} 30 \mathrm{WAVE}$, less well localized by the SST anomalies, although there remains a substantial asymmetry in the geopotential height variance at $850 \mathrm{hPa}$ (Fig. 12a). The storm track is strongest downstream of the enhanced SST gradients associated with the cold SST anomaly (at $40^{\circ} \mathrm{N}, 270^{\circ} \mathrm{E}$ ) and weakest in the region of the suppressed SST gradients (at $40^{\circ} \mathrm{N}, 90^{\circ} \mathrm{E}$ ), consistent with the modification of the lower-tropospheric baroclinicity by the SST gradients
(Fig. 12d). Changes in the tropical distribution of precipitation (and therefore the tropically driven component of the subtropical jet) are small (Figs. 12b,c).

The changes in the eddy feedback on the flow in 3K50WAVE are also relatively small (Fig. 10b), with the heat flux capable of maintaining a zonal asymmetry in the surface winds of approximately $2 \mathrm{~m} \mathrm{~s}^{-1}$ at $40^{\circ}-$ $45^{\circ}$ latitude. The phase relationship of this forcing is again consistent with the actual zonal winds at $1000 \mathrm{hPa}$ (Fig. 11b). It is also consistent with the phase of the weak variation of the tropical precipitation (Fig. 12b), assuming that this reflects the driving of the Hadley cell by the extratropical transients.

As in experiment $3 \mathrm{~K} 30 \mathrm{WAVE}$, the mean sea level pressure pattern features a low pressure downstream and to the poleward side of the intensified SST gradients and a high pressure downstream and poleward of the weakened SST gradients. This pressure signal again has an approximately barotropic character (Fig. 11d), but the signal is weaker (cf. Figs. 11b,d with Figs. 11a,c, respectively).

While the character of the response to the SST gradient changes in experiments $3 \mathrm{~K} 30 \mathrm{WAVE}$ and 3K50WAVE is similar, it is perhaps surprising that the zonal asymmetry in the 3K50WAVE storm track is relatively weak when compared to $3 \mathrm{~K} 30 \mathrm{WAVE}$, as the difference between the peak storm-track intensities in the zonally uniform experiments $3 \mathrm{~K} 50+$ and $3 \mathrm{~K} 50-$ is larger than that between those in $3 \mathrm{~K} 30+$ and $3 \mathrm{~K} 30-$ (Fig. 5). This difference in the level of asymmetry may potentially be attributed to a number of factors.

First, the cold part of experiment 3K30WAVE (similar to $3 \mathrm{~K} 30-$ ) strongly modifies the subtropical jet up- 
(a) 3K3OWAVE: MSLP, U1000

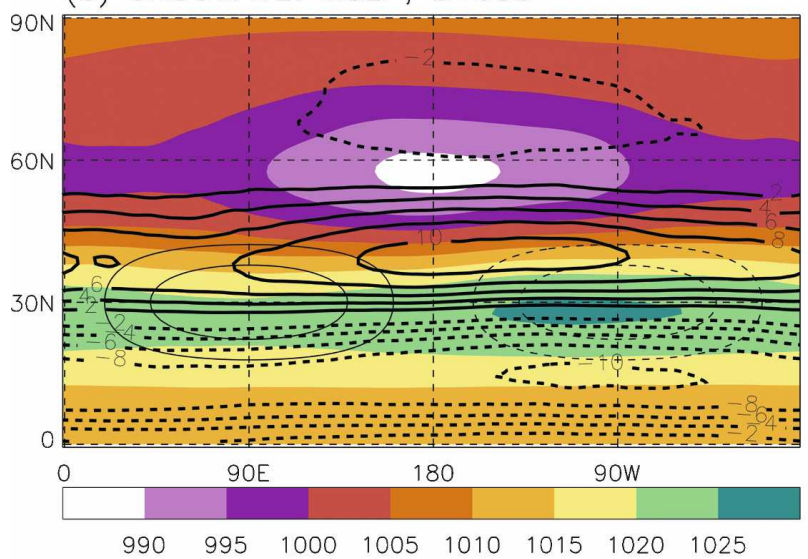

(c) 3K3OWAVE: SFN 700, 250

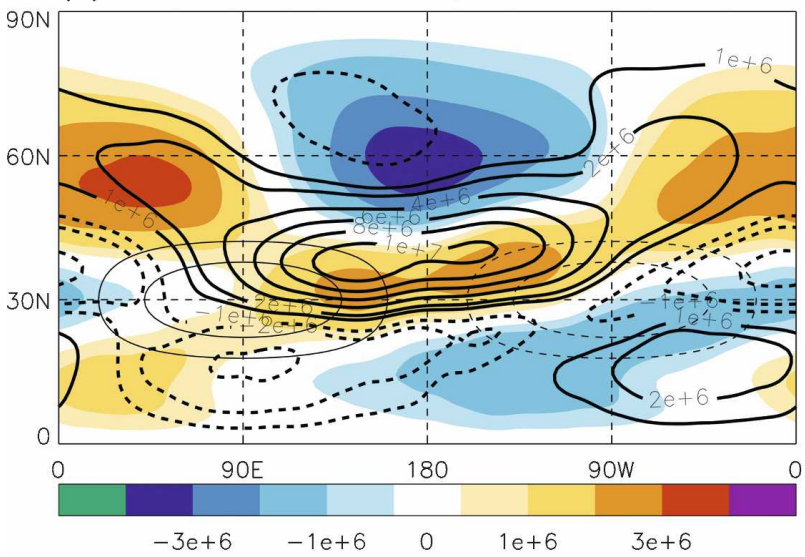

(b) 3K50WAVE: MSLP, U1000

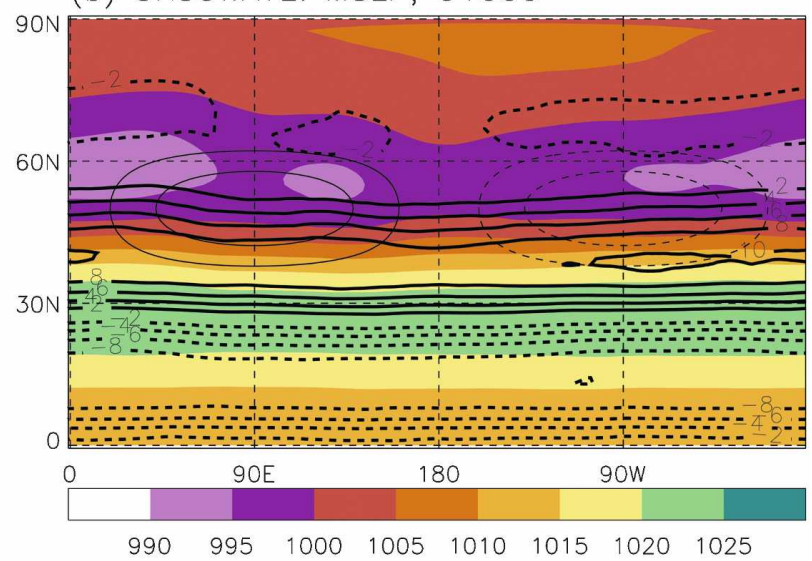

(c) 3K5OWAVE: SFN 700, 250

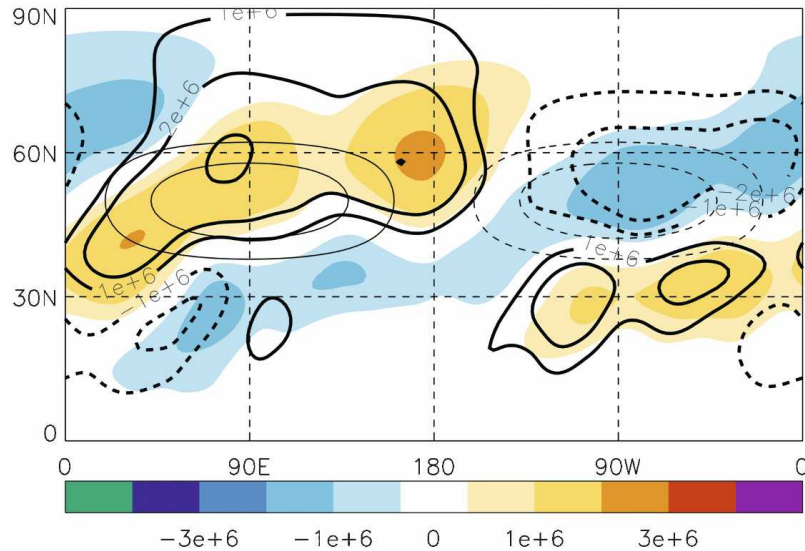

FIG. 11. Tropospheric response patterns for the asymmetric experiments: (a), (b) MSLP (shading, hPa) and zonal wind at $1000 \mathrm{hPa}$ (contours every $2 \mathrm{~m} \mathrm{~s}^{-1}$, dashed for negative) for experiments 3K30WAVE and 3K50WAVE, respectively. (c), (d) Streamfunction anomalies relative to the control run at 700 (colors) and $250 \mathrm{hPa}$ (thick contours at $\pm 1,2,4,6,8,10 \times 10^{6} \mathrm{~m}^{2} \mathrm{~s}^{-1}$, dashed for negative) for experiments 3K30WAVE and 3K50WAVE, respectively. In each panel, thin contours mark the SST anomalies.

stream of the enhanced midlatitude SST gradients associated with the warm part of the SST pattern (similar to $3 \mathrm{~K} 30+$ ), increasing the baroclinicity of the upper troposphere immediately on the poleward side of the subtropical jet. This is consistent with stronger storm activity over the downstream region near $35^{\circ}-40^{\circ} \mathrm{N}$, $80^{\circ}-90^{\circ} \mathrm{E}$ (Fig. 10a), whereas, from experiment $3 \mathrm{~K} 30+$, one might expect to find a reduction in storm activity in this region (Fig. 5c). Similarly, the warm part of experiment 3K30WAVE (similar to 3K30+) weakens the upper-tropospheric baroclinicity associated with the subtropical jet, further exacerbating the weakening of the storm track in the downstream region (near $40^{\circ}-45^{\circ} \mathrm{N}$, $270^{\circ} \mathrm{E}$ in Fig. 10a). In contrast, for the 3K50WAVE experiment there is no such tropically forced asymmetry in the subtropical jet and the response more clearly follows a progression from a state similar to that of experiment $3 \mathrm{~K} 50+$ to one similar to experiment $3 \mathrm{~K} 50-$.
Second, latent heat release is expected to promote storm growth. In experiment 3K30WAVE, the enhanced storm track and SST gradients are associated with the warm SST anomaly. There is therefore the possibility of additional moisture available to increase the latent heat source, which can aid rapid storm growth in the region immediately surrounding the enhanced SST gradient. Conversely, there is an anomalously weak latent heat source close to the weak SST gradients (near the cold SST anomaly), helping to further weaken the storm track (Fig. 8b). The latent heat release therefore may act to aid the localization of the storm track. The situation is reversed in experiment 3K50WAVE (Fig. $12 \mathrm{~b}$ ), with the possibility of a reduced latent heat source near the enhanced SST gradient at $40^{\circ} \mathrm{N}, 270^{\circ} \mathrm{E}$ (where the storm track is strong) and an enhanced potential latent heat source farther downstream (where the storm track is weak). In experi- 
(a) Geopotential height variance $850 \mathrm{hPa}$

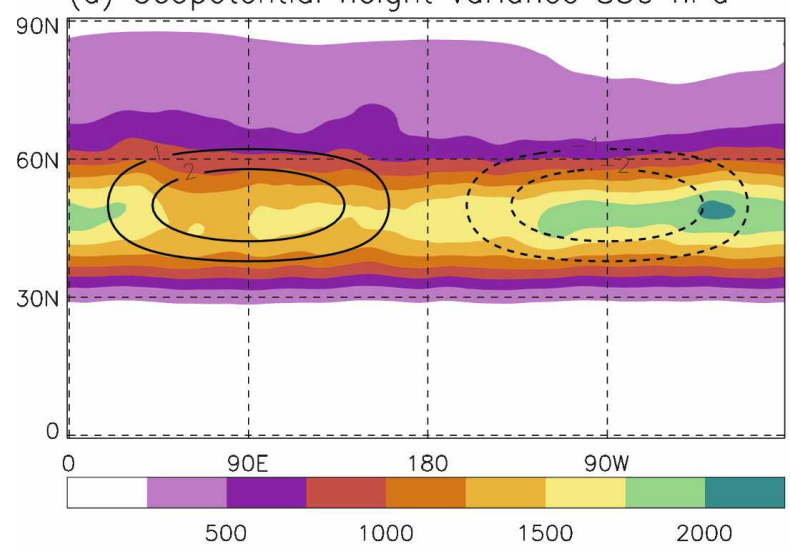

(c) Zonal wind $250 \mathrm{hPa}$

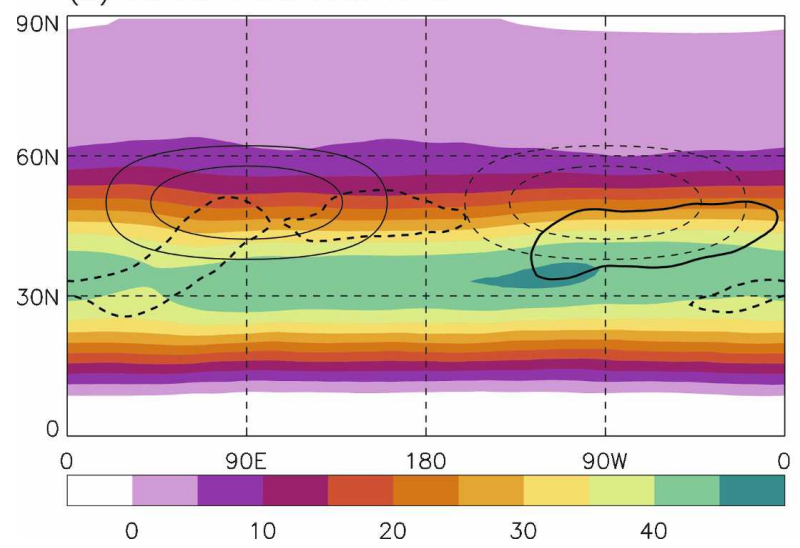

(b) Precipitation

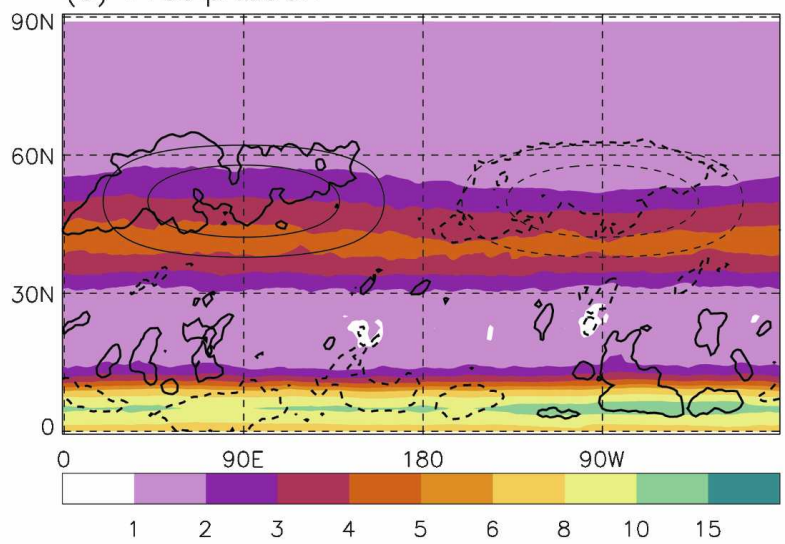

(d) Eady $850 \mathrm{hPa}$

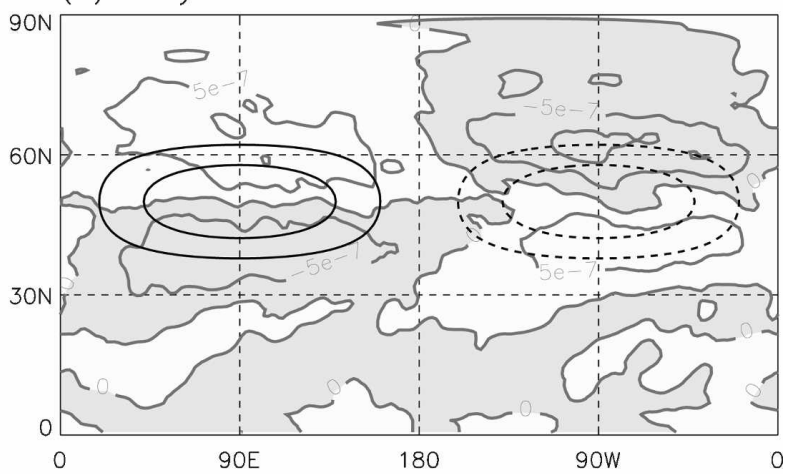

FIG. 12. Experiment 3K50WAVE: (a) Bandpass-filtered geopotential height variance at $850 \mathrm{hPa}\left(\mathrm{m}^{2}\right)$. (b) Precipitation: absolute in $\mathrm{mm} \mathrm{day}^{-1}$ (shading) and anomaly relative to control run shown by contours at \pm 0.25 and $1 \mathrm{~mm} \mathrm{day}^{-1}$. (c) Zonal wind at $250 \mathrm{hPa}$ : absolute in $\mathrm{m} \mathrm{s}^{-1}$ (shading) and anomaly relative to control run shown by thick contours at $\pm 2,4,6 \mathrm{~m} \mathrm{~s}^{-1}$. (d) Eady growth rate anomaly (between 925 and $775 \mathrm{hPa}, \mathrm{s}^{-1}$ ) relative to control run, shaded for negative. In each panel, thin contours mark the SST anomalies.

ment 3K50WAVE, the latent heat availability therefore may work against the localization of the storm track.

Interestingly, however, in terms of zonally averaged measures of the storm track (not shown), the $3 \mathrm{~K} 30 \mathrm{WAVE}$ storm track is marginally weaker than that of the control run, indicating that the reduction of storm activity by the cold part of the SST pattern is stronger than the enhancement in storm activity by the warm part (see also Figs. 9b and 10a). This is the opposite to that expected from Clausius-Clapeyron-based arguments: the warmer SSTs should provide a stronger positive anomaly in latent heat release than the reduction of latent heat release by the colder SSTs, suggesting that the storm-track intensification should outweigh the storm-track weakening in experiment 3K30WAVE. This perhaps provides further evidence that the structure of the SST gradient anomalies and their relation- ship to the tropically driven component of the subtropical jet is of more importance to the atmospheric response than changes in latent heat availability due to the sense of the extratropical SST anomaly.

The overall response patterns in the storm track and upper-tropospheric jet discussed in this section are broadly consistent with those seen in a similar study by Inatsu et al. (2003). They suggest that zonally localized condensational heating in the storm track is the primary mechanism for maintaining the response pattern in the upper troposphere, and that these patterns lead to increased vertical shear in the lower troposphere, giving a positive feedback on the storm track. However, on the basis of the findings presented here, an alternative interpretation is to consider the latent heating as an amplifier of a tropospheric response pattern that is generated by the anomalies in the SST gradient (particularly in the subtropics). 


\section{Interpretation of some earlier studies}

The understanding of the sensitivity of the tropospheric response (particularly in terms of the midlatitude storm track) to the position of SST gradients relative to the tropically driven component of the subtropical jet discussed above gives a basis for reconsidering the SST anomaly experiments performed by Peng et al. (1995, hereafter P95), Ting and Peng (1995, hereafter T95), Peng et al. (1997, hereafter P97), and Peng and Whitaker (1999, hereafter P99). The discussion in these studies, in common with many previous authors, focused on the tropospheric response to a SST anomaly rather than to changes in the SST gradients.

In P95 and T95, a SST anomaly was introduced into the North Atlantic region and the response was examined for two different climatological background states: perpetual November and perpetual January. Under the November conditions a barotropic high was produced downstream of the anomaly, whereas in January the response was a barotropic low.

The SST anomalies used in P95 and T95 are introduced into a zonally asymmetric model (including landmasses, orography, etc.) and into the North Atlantic, which, as already noted, has a somewhat different structure of SST gradients to the QOBS profile used here. However, it is still relevant to highlight two important features of their experiments:

- The warm SST anomaly leads to SST gradients enhanced on the poleward side and reduced on the equatorward side.

- The tropically driven component of the subtropical jet can be expected to be positioned farther equatorward in the January case compared with the November case (although this is difficult to discern directly from the figures in either paper).

In the January case the equatorward shift of the tropically driven subtropical jet component is consistent with the increased SST gradients on the poleward side of the SST anomaly falling into the high latitude category in Table 2: the anomalously strong SST gradient region lies far poleward of the subtropical jet. The impact of this SST gradient increase on the storm track and the jet structure is therefore likely to be minimal. The SST gradient decrease on the south side of the anomaly, however, lies closer toward (but still poleward of) the subtropical jet, that is, in the midlatitude category of Table 2. This is therefore consistent with a weaker, southward shifted storm track and a jet structure that is more subtropically dominated (i.e., shifted equatorward and more baroclinic). The actual storm tracks and jet structure produced in these integrations are consistent with this interpretation (P95, their Fig. 11 shows a weakened storm track; T95, their Fig. 2 shows an equatorward shift in the jet).

Conversely, in November, with the tropically driven component of the subtropical jet farther poleward, the increased SST gradients on the poleward side of the SST anomaly can be expected to have more influence, akin to those of the midlatitude category in Table 2, enhancing the storm track and acting to strengthen the eddy-driven jet. Furthermore, the decreased SST gradients on the equatorward side of the SST anomaly are now closer to the subtropics, making their effect similar to the subtropical category in Table 2 , shifting the storm track and jet poleward. The actual storm track in these simulations is enhanced near Newfoundland and the far North Atlantic and suppressed over the mid-Atlantic to the west of Spain (P95, their Fig. 10), associated with a poleward shift in the jet in the "North West" Atlantic (shown in T95, their Fig. 2), consistent with these expectations.

Describing these eddy-driven shifts in the jet in terms of height or streamfunction anomalies, then the same SST anomaly gives an equivalent barotropic low/ cyclone to the north and high/anticyclone to the south downstream of the SST anomaly in November (and the reverse for January). This then gives an interpretation of the barotropic high/low patterns described by P95 and T95. Further experiments featuring a more detailed "semirealistic" North Atlantic will also be presented in subsequent papers based on Brayshaw (2006). Similar arguments, focusing on the impacts of SST gradients on the relative strengths of the eddy-driven jets can also perhaps be applied to the later papers P97 and P99, although it is difficult to confirm this using the figures in those papers.

\section{Conclusions}

A series of aquaplanet GCM simulations has been performed with idealized boundary conditions to assess the atmospheric response to midlatitude changes in sea surface temperature. These simulations have provided a framework for understanding the response to extratropical SST anomalies in terms of the location of the implied anomalies in SST gradients.

For zonally symmetric aquaplanets, stronger SST gradients on the poleward side of the subtropical jet generally lead to a stronger storm track and eddydriven jet. This increased intensity is accompanied by a slight poleward shift of the storm track (and jet) as the storm track becomes more closely associated with the midlatitude SST front rather than the tropically driven component of the subtropical jet. In some cases (such as 
experiment $3 \mathrm{~K} 30+$ ) this can lead to a separation of the eddy-driven jet from the subtropical jet. Conversely, if the SST gradients are weakened, the storm track and eddy-driven jets are weakened and shifted slightly equatorward as they become more closely associated with the tropically driven component of the subtropical jet. The impact of such changes in the SST gradients, however, decreases at higher latitudes such that SST gradient anomalies far poleward of the subtropical jet create only a very weak response.

The tropospheric response to SST gradient anomalies that lie very close to (or equatorward of) the subtropical jet is, however, very different. In this case, an increase in SST gradient tends to enhance the tropically driven Hadley cell, producing a stronger and more baroclinic subtropical jet. This is consistent with a stronger storm track, but also leads to an equatorward shift of the storm-track and the eddy-driven jet. The increases in storm-track intensity through this process may, however, be limited ultimately by mechanisms such as the barotropic governor (James 1987) and eddy trapping (Nakamura and Sampe 2002). In the reverse situation where the subtropical SST gradients are reduced, the Hadley cell is weakened leading to a poleward shift and weakening of the storm track. Overall, these findings are generally consistent with the observations and arguments given by Nakamura et al. (2004).

The difference between the tropical and extratropical response to SST gradient anomalies means that SST anomalies that lie close to the latitude of the subtropical jet are very effective at modifying the tropospheric flow patterns and the storm track. In particular a warm SST anomaly at the poleward edge of the subtropics both weakens the tropically driven component of the subtropical jet (thereby shifting the storm track poleward) and also increases the midlatitude SST gradients (also shifting the storm track poleward and intensifying it). In more realistic simulations, however, the precise latitude of this region that produces this large stormtrack response to a SST anomaly will vary depending on the background SST profile and the seasonal march of the Hadley cell.

Experiments featuring zonally asymmetric SST distributions confirm the importance of the SST gradient in determining the atmospheric response. In particular, the equivalent barotropic enhancement of the eddydriven jet produced by an increase in the midlatitude SST gradient is consistent with enhanced westerlies and the formation of a low downstream and poleward of the region of enhanced SST gradient. Conversely, suppressed SST gradients lead to a weaker eddy-driven jet and a high on the poleward side of the anomalous SST gradients.
The sign of the intensification/weakening of the storm track and eddy-driven jet by the anomalous SST gradients is seen irrespective of the sign of the SST anomaly producing the gradient change. However, the modulation of the storm track is relatively weak in the 3K50WAVE experiment compared to the 3K30WAVE experiment. This difference in the storm tracks between the two experiments is consistent with both changes in the subtropical jet structure produced by the curvature of the tropical SST profile (as described in the zonally symmetric SST experiments) and also with changes in the availability of latent heat supply (the storm-track enhancement in 3K30WAVE takes place over warm water, potentially providing an additional latent heat source for storm growth; the situation is reversed for experiment 3K50WAVE).

The sensitivity of the atmospheric response to the SST gradients around the subtropical jet is clearly important for accurate coupled atmosphere-ocean climate simulations. In particular, the SST distribution in the subtropics and midlatitudes has been shown here to have a profound effect on the storm-track structure, the eddy-driven jet, and the surface winds. The surface wind stress exerted on the ocean may then act to modify the subtropical gyres in the oceans and hence the SST distributions, potentially further modifying the storm track. Such feedbacks need to be considered when changing the various components of a coupled model (e.g., when the resolution is increased in either the atmosphere or the ocean model).

Equally, care should be taken with atmosphere-only models driven by prescribed SST fields. In such simulations, if the subtropical jet is incorrectly located in the model then the position of gradients in the SST distribution relative to it may be incorrect, potentially producing significant differences through the model's storm-track response.

Although experiments such as 3K30WAVE produce interesting similarities with observed storm-track and jet structures in oceanic regions, further work is required to relate the results discussed in this study to the observed storm tracks. The SST anomalies considered here are at most zonal wavenumber 1 , which is significantly larger than the typical scale of SST anomalies in the real world. It is also necessary to assess the effects of other boundary condition asymmetries such as landsea contrast and orography. These issues will be addressed in a similar, near-aquaplanet, framework in subsequent papers.

Acknowledgments. The authors thank H. Nakamura for his thorough and helpful review, which has led to many improvements in the text. This work was sup- 
ported by the NERC Rapid Climate Change Pro- and gramme, project reference NER/T/S/2002/00441.

\section{APPENDIX}

\section{Estimation of Eddy-Driven Surface Westerly Wind using E Vectors}

Following HJW, for nondivergent motion, the transient eddy vorticity flux can be written in terms of the anisotropic velocity correlation tensor:

$$
\overline{\mathbf{v}^{\prime} \zeta^{\prime}}=-\mathbf{k} \times(\boldsymbol{\nabla} \cdot \mathbf{A})
$$

where

$$
\mathbf{A}=\left(\begin{array}{cc}
M & N \\
-N & -M
\end{array}\right)
$$

and

$$
M=\frac{1}{2}\left(\overline{u^{\prime 2}-v^{\prime 2}}\right), \quad N=\overline{u^{\prime} v^{\prime}} .
$$

Therefore the forcing of the mean flow vorticity is

$$
\bar{D} \bar{\zeta}=-\boldsymbol{\nabla} \cdot \overline{v^{\prime} \zeta^{\prime}}=-\mathbf{k} \cdot(\boldsymbol{\nabla} \times \boldsymbol{\nabla} \cdot \mathbf{A}),
$$

where $\bar{D}$ is a mean flow advection operator.

Since it is difficult to derive insight from this form, HJW made an approximation in the right-hand side of Eq. (A4) based on the small latitudinal-longitudinal aspect ratio of storm tracks and showed that

$$
\bar{D} \bar{\zeta} \approx-\frac{\partial}{\partial y} \boldsymbol{\nabla} \cdot \mathbf{E}_{H},
$$

where the horizontal $\mathbf{E}$ vector is given by

$$
\mathbf{E}_{H}=(-2 M,-N)=\left(\overline{v^{\prime 2}-u^{\prime 2}},-\overline{u^{\prime} v^{\prime}}\right) .
$$

The same aspect ratio scaling for the time-mean flow implies that the time-mean vorticity is approximately $-\partial \bar{u} / \partial y$ so that Eq. (A5) implies that the eddy vorticity forcing of the mean rotational flow is as if $\bar{u}$ was forced by $\boldsymbol{\nabla} \cdot \mathbf{E}_{H}$.

Further, following appendix A of HJW, with a redefinition of the ageostrophic flow, the eddy forcing in the mean $y$-momentum equation is negligible and baroclinic effects can also be incorporated. The mean $x$ momentum equation can then be written

$$
\bar{D} \bar{u}=f \bar{v}_{\mathrm{am}}+\boldsymbol{\nabla} \cdot \mathbf{E}-\lambda \bar{u},
$$

where $\bar{v}_{\mathrm{am}}$ is the modified ageostrophic meridional velocity and $\mathbf{E}=\mathbf{E}_{H}+E_{z} \mathbf{k}$. The vertical $\mathbf{E}$ vector is given by

$$
E_{z}=f \frac{B}{N^{2}}
$$

$$
B=\overline{v^{\prime} \frac{g}{\theta_{0}} \theta^{\prime}} .
$$

Linear drag near the surface is included with inverse time scale $\lambda$.

Typically in the zonal average of a storm-track region, $\boldsymbol{\nabla} \cdot \mathbf{E}_{H}$ is positive in the upper troposphere, acting to accelerate the westerly winds. This is compensated to a greater or lesser extent by the convergence above the lower-tropospheric maximum in $E_{z}$. Below this maximum there is divergence, the extent of which is determined by the near-surface value of $E_{z}$. In the vertical integral the net impact of $E_{z}$ is zero because its nonzero surface value is exactly compensated by a net poleward mass flux. Thus $\boldsymbol{\nabla} \cdot \mathbf{E}_{H}$ alone drives the westerly flow and is balanced by surface drag.

In a local storm-track region the impact of the vertical and horizontal components of $\mathbf{E}$ will, in general, occur at different longitudes. Also the modified meridional circulation will be three-dimensional. However, we wish to use Eq. (A7) to suggest simple normalizations of $\boldsymbol{\nabla} \cdot \mathbf{E}_{H}$ and $E_{z}$ that allow comparisons with the actual surface flow.

We consider first the impact of the eddy vorticity forcing only (i.e., $\boldsymbol{\nabla} \cdot \mathbf{E}_{H}$ ) and the simple situation in which the eddy westerly wind forcing is in an uppertropospheric layer of depth $h_{1}$ and density $\rho_{1}$, while the drag acts in a lower layer of depth $h_{2}$ and density $\rho_{2}$ on a wind $u_{2}$. With the approximation that the modified ageostrophic velocity obeys mass balance (integrates to zero), the vertical integral of Eq. (A7) gives

$$
u_{2}=\frac{1}{\lambda} \frac{\rho_{1} h_{1}}{\rho_{2} h_{2}} \boldsymbol{\nabla} \cdot \mathbf{E}_{H} .
$$

Therefore $\boldsymbol{\nabla} \cdot \mathbf{E}_{H}$ can be scaled as in Eq. (A10) to give an estimate of the near-surface equilibrium eddydriven westerlies. Here, we use $h_{1} / h_{2}=3, \rho_{1} / \rho_{2}=1 / 2$, and $\lambda=1.7 \times 10^{-5} \mathrm{~s}^{-1}$ (giving an $e$-folding time of 0.7 day $^{-1}$ ); therefore, we scale $\boldsymbol{\nabla} \cdot \mathbf{E}_{H}$ by the factor $0.9 \times$ $10^{5} \mathrm{~s}$

The transient eddy heat flux at the lower to mid tropospheric levels, $E_{z}$, can similarly be scaled in terms of an estimate of the equilibrium westerly wind that would exist in the presence of low-level drag and zero lowlevel $\bar{v}_{\text {am }}$. Consider the situation where divergence of the vertical $\mathbf{E}$ vector balances drag acting on a westerly flow $u_{2}$ in a near-surface layer of depth $h_{2}$. With $E_{z}$ at height $h_{2}$ and zero at the surface, Eq. (A7) gives

$$
u_{2}=\frac{1}{\lambda h_{2}} E_{z} .
$$


In pressure coordinates the equivalent is

$$
u_{2}=-\frac{1}{\lambda \Delta p} E_{p}
$$

where

$$
E_{p}=f \frac{\overline{v^{\prime} \theta^{\prime}}}{\Theta_{p}} .
$$

Here we use the $850-\mathrm{hPa} E_{p}$ and scale it with the factor as in Eq. (A12), with $\Delta p=150 \mathrm{hPa}$ and $\lambda$ as previously.

As in the above zonal average discussion, Eqs. (A11) and (A12) are likely to be an overestimate of the equilibrium surface wind, as $E_{z}$ will not in reality decrease to zero at the surface. However, using the normalized forms of $\boldsymbol{\nabla} \cdot \mathbf{E}_{H}$ evaluated at $250 \mathrm{hPa}$ and $E_{p}$ evaluated at $850 \mathrm{hPa}$ enables comparison with the actual lowerlevel westerlies, and between experiments. For the zonally averaged situation the two estimates of the surface wind should be consistent. This can be shown to be the case provided a finite difference version of $\boldsymbol{\nabla} \cdot \mathbf{E}$ in the upper troposphere is satisfied.

\section{REFERENCES}

Brayshaw, D. J., 2006: Large scale forcing of the North Atlantic storm track. Ph.D. thesis, University of Reading, 213 pp.

Cash, B. A., P. A. Kushner, and G. K. Vallis, 2005: Zonal asymmetries, teleconnections, and annular patterns in a GCM. $J$. Atmos. Sci., 62, 207-219.

Duchon, C. E., 1979: Lanczos filtering in one and two dimensions. J. Appl. Meteor., 18, 1016-1022.

Edmon, H. J., B. J. Hoskins, and M. E. McIntyre, 1980: EliassenPalm cross sections for the troposphere. J. Atmos. Sci., 37, 2600-2616.

Greeves, C. Z., V. D. Pope, R. A. Stratton, and G. M. Martin, 2007: Represenation of northern hemisphere winter storm tracks in climate models. Climate Dyn., 28, 683-702.

Held, I. M., and A. Y. Hou, 1980: Nonlinear axially symmetric circulations in a nearly inviscid atmosphere. J. Atmos. Sci., 37, $515-533$.

Hoskins, B. J., and P. J. Valdes, 1990: On the existence of storm tracks. J. Atmos. Sci., 47, 1854-1864.

—, I. N. James, and G. H. White, 1983: The shape, propagation and mean-flow interaction of large-scale weather systems. $J$. Atmos. Sci., 40, 1595-1612.

Inatsu, M., H. Mukougawa, and S.-P. Xie, 2002: Stationary eddy response to surface boundary forcing: Idealized GCM experiments. J. Atmos. Sci., 59, 1898-1915.

,-- , and -2003 : Atmospheric response to zonal variations in midlatitude SST: Transient and stationary eddies and their feedback. J. Climate, 16, 3314-3329.

James, I. N., 1987: Suppression of baroclinic instability in horizontally sheared flows. J. Atmos. Sci., 44, 3710-3720.

Kim, H.-K., and S. Lee, 2001: Hadley cell dynamics in a primitive equation model. Part II: Nonaxisymmetric flow. J. Atmos. Sci., 58, 2859-2871.

Kushnir, Y., and I. M. Held, 1996: Equilibrium atmospheric re- sponse to North Atlantic SST anomalies. J. Climate, 9, 1208 1220.

— W. A. Robinson, I. Blade, N. M. J. Hall, S. Peng, and R. Sutton, 2002: Atmospheric GCM response to extratropical SST anomalies: Synthesis and evaluation. J. Climate, 15, 2233-2256.

Lee, S., and H.-K. Kim, 2003: The dynamical relationship between subtropical and eddy-driven jets. J. Atmos. Sci., 60, 14901503.

Nakamura, H., and T. Sampe, 2002: Trapping of synoptic-scale disturbances into the North-Pacific subtropical jet core in midwinter. Geophys. Res. Lett., 29, 1761, doi:10.1029/ 2002GL015535.

— , and A. Shimpo, 2004: Seasonal variations in the Southern Hemisphere storm tracks and jet streams as revealed in a reanalysis dataset. J. Climate, 17, 1828-1844.

—, T. Sampe, Y. Tanimoto, and A. Shimpo, 2004: Observed associations among storm tracks, jet streams, and midlatitude oceanic fronts. Earth's Climate: The Ocean-Atmosphere Interaction, Geophys. Monogr., Vol. 147, Amer. Geophys. Union, 329-345.

Neale, R. B., and B. J. Hoskins, 2000: A standard test for AGCMs including their physical parameterisations I: The proposal. Atmos. Sci. Lett., 1, 101-107.

Peng, S., and J. S. Whitaker, 1999: Mechanisms determining the atmospheric response to midlatitude SST anomalies. J. Climate, 12, 1393-1408.

— L. A. Mysak, H. Ritchie, J. Derome, and B. Dugas, 1995: The differences between early and midwinter atmospheric responses to sea surface temperature anomalies in the Northwest Atlantic. J. Climate, 8, 137-157.

— W. A. Robinson, and M. P. Hoerling, 1997: The modeled atmospheric response to midlatitude SST anomalies and its dependence on background circulation states. J. Climate, 10, 971-987.

Pope, V. D., and R. A. Stratton, 2002: The processes governing horizontal resolution sensitivity in a climate model. Climate Dyn., 19, 211-216.

- M. L. Gallani, R. R. Rowntree, and R. A. Stratton, 2000: The impact of new physical parameterizations in the Hadley Centre climate model: HadAM3. Climate Dyn., 16, 123-146.

Simmons, A. J., and B. J. Hoskins, 1978: The life cycles of some nonlinear baroclinic waves. J. Atmos. Sci., 35, 414-432.

$\longrightarrow$, and - 1980: Barotropic influences on the growth and decay of nonlinear baroclinic waves. J. Atmos. Sci., 37, 16791694.

Stratton, R. A., 2004: Report on aspects of variability in highresolution versions of HadAM3. Hadley Centre Tech. Note 53, 31 pp. [Available from Met Office, FitzRoy Road, Exeter, Devon, EX1 3PB, United Kingdom.]

Thorncroft, C. D., B. J. Hoskins, and M. E. McIntyre, 1993: Two paradigms of baroclinic-wave life-cycle behaviour. Quart. J. Roy. Meteor. Soc., 119, 17-55.

Ting, M., and S. Peng, 1995: Dynamics of the early and middle winter atmospheric responses to the northwest Atlantic SST anomalies. J. Climate, 8, 2239-2254.

Trenberth, K. E., and D. P. Stepaniak, 2003: Seamless poleward atmospheric energy transports and implications for the Hadley circulation. J. Climate, 16, 3706-3722.

Uppala, S. M., and Coauthors, 2005: The ERA-40 Re-Analysis. Quart. J. Roy. Meteor. Soc., 131, 2961-3012.

Wilks, D. S., 1995: Statistical Methods in the Atmospheric Sciences. Academic Press, 467 pp. 